\title{
Human augmentation: Past, present and future
}

\author{
Roope Raisamo, Ismo Rakkolainen, Päivi Majaranta, \\ Katri Salminen, Jussi Rantala and Ahmed Farooq
}

\begin{abstract}
Affiliation:
Tampere Unit for Computer-Human Interaction (TAUCHI) Faculty of Information Technology and Communication Sciences Tampere University \{roope.raisamo, ismo.rakkolainen, paivi.majaranta, katri.salminen, jussi.rantala, ahmed.farooq\}@tuni.fi
\end{abstract}

Corresponding author:

Roope Raisamo

roope.raisamo@tuni.fi

Phone: +358-50-5702-007

Postal address:

Tampere University

Kanslerinrinne 1, FI-33014 Tampere, Finland 


\begin{abstract}
Human augmentation is a field of research that aims to enhance human abilities through medicine or technology. This has historically been achieved by consuming chemical substances that improve a selected ability or by installing implants which require medical operations. Both of these methods of augmentation can be invasive. Augmented abilities have also been achieved with external tools, such as eyeglasses, binoculars, microscopes or highly sensitive microphones. Lately, augmented reality and multimodal interaction technologies have enabled non-invasive ways to augment human.

In this article, we first discuss the field and related terms. We provide relevant definitions based on the present understanding of the field. This is followed by a summary of existing work in augmented senses, action, and cognition. Our contribution to the future includes a model for wearable augmentation. In addition, we present a call for research to realize this vision. Then, we discuss future human abilities. Wearable technologies may act as mediators for human augmentation, in the same manner as eyeglasses once revolutionized human vision. Non-invasive and easy-to-use wearable extensions will enable lengthening the active life for aging citizens or supporting the full inclusion of people with special needs in society, but there are also potential problems. Therefore, we conclude by discussing ethical and societal issues: privacy, social manipulation, autonomy and side effects, accessibility, safety and balance, and unpredictable future.
\end{abstract}

\title{
Keywords
}

human augmentation, augmented reality, wearable computing, multimodal interaction, crossmodal interaction, augmented senses, augmented action, augmented cognition, interaction paradigms

\section{Introduction}

Since the invention of direct manipulation and graphical user interfaces (Sutherland, 1963; Engelbart, 1968; Shneiderman, 1982; Lipkie et al., 1982), the developments in mainstream human-technology interaction have been incremental. They enable to use the tools in more direct, efficient and robust ways, but the underlying model of interaction is still the same: the notion that a computing device is a tool. More recently, the research focus in the field has moved to mobile and pervasive interaction, including embodied interfaces (Fishkin et al., 1998) and intelligent user interfaces (Maybury and Wahlster, 1998). However, there is still a clear separation between the user and the system.

In the past, humans had to adapt to computers. In the future, computers will adapt to humans. Here we use the term 'natural' when referring to interaction that closely resembles the innate ways humans act and interact with physical objects. It is important to define this term due to varied interpretations of the word 'natural' in the literature (Hansen and Dalsgaard, 2015; O'Hara et al., 2013). There are several technologies and user interface (UI) paradigms which have aimed to make the interaction more natural and efficient. Today, a user can direct a system, for example, with speech, gestures, eye gaze, or even through human electrophysiological signals. The system can acquire data through different sensors and provide the user with information through various modalities in real-time, including visual, auditory and haptic presentations. Increasingly, different input and output modalities 
are being combined within the same task, such as simultaneous auditory and haptic notification of interesting events within the surrounding environment.

Human-centric user interface paradigms include perceptual interfaces (Turk, 2014), augmented reality (AR) (Schmalstieg and Höllerer, 2016), virtual reality (VR) (van Krevelen and Poelman, 2010; Jerald, 2015), and ubiquitous computing (Weiser, 1993). Fig. 1 illustrates some of these paradigms. Human augmentation is a paradigm that builds on top of these earlier paradigms by combining the interaction where human action is the core. These actions are supported with augmenting technologies that are related to perceiving, affecting, or cognitively processing the world and information around the user.

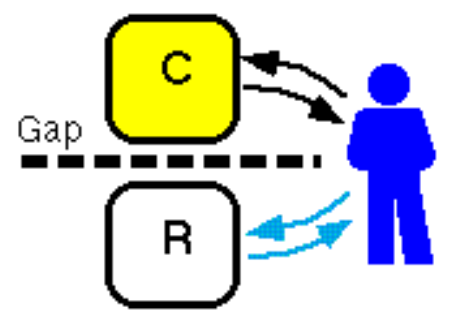

(a) GUI



(c) Ubiquitous Computers

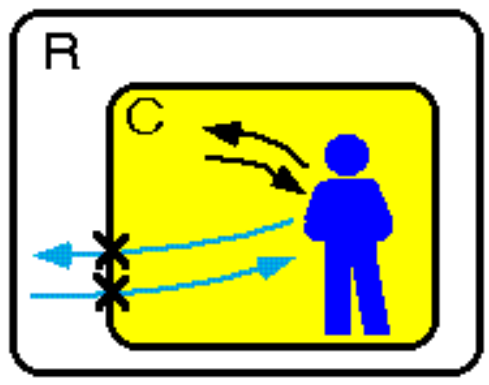

(b) Virtual Reality

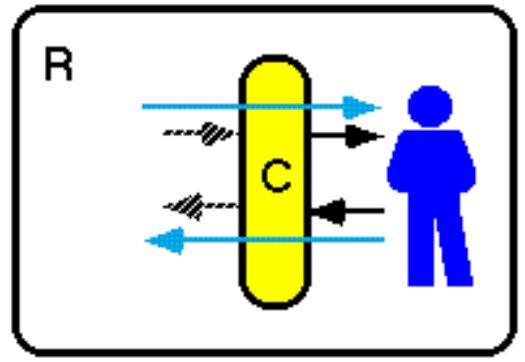

(d) Augmented Interaction
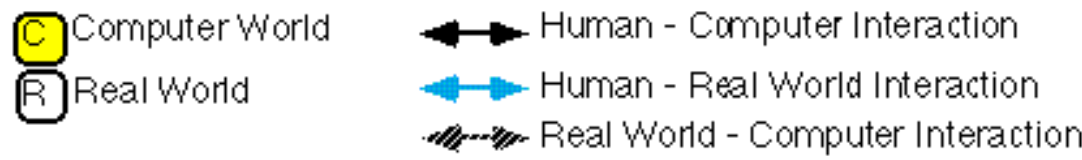

Fig. 1. Different user interface paradigms (Rekimoto and Nagao, 1995).

There are a few related terms closely connected to human augmentation. Human enhancement is a broad field covering several disciplines from electrical or mechanical to genetic engineering. Moore (2008), defines it as "any attempt to temporarily or permanently overcome the current limitations of the human body through natural or artificial means. It is the use of technological means to select or alter human characteristics and capacities, whether or not the alteration results in characteristics and capacities that lie beyond the existing human range." Human enhancement can cover means and solutions which require surgical operations (e.g., Suthana et al., 2012) or chemical stimulants that can be used, for example, to improve attention control (e.g., Robbins, 2005). Such methods are not connected to human-technology interaction and are thus omitted from this article. 
Human augmentation (Alicea, 2018) and related concepts Augmented Human ${ }^{1}$ and Human $2.0^{2}$ refer to technologies that enhance human productivity or capability, or that somehow add to the human body or mind. Modern advancements in science and technology have led to a great variety of implants and other technologies that could be classified as human augmentation. Augmentation is the most common term in the interdisciplinary research community that focuses on interactive digital extensions of human abilities. There is a conference series called Augmented Human ${ }^{1}$ (AH) and a dedicated journal, Augmented Human Research ${ }^{3}$ that advance the field. Thus, we have chosen the term human augmentation over human enhancement that is not commonly used in this context.

It turns out that human augmentation as a field is still so young that there is no commonly agreedupon definition even though the number of articles and books on the topic is increasing. In her book entitled 'Augmented Human', Papagiannis (2017) focuses mainly on the potential of augmented reality and offers no definition for the field. For the purpose of this article and the whole research community, we present the following definition:

Human augmentation is an interdisciplinary field that addresses methods, technologies and their applications for enhancing sensing, action and/or cognitive abilities of a human. This is achieved through sensing and actuation technologies, fusion and fission of information, and artificial intelligence (AI) methods.

Human augmentation can further be divided into three main categories of augmentation:

- Augmented senses (aka enhanced senses, extended senses) are achieved by interpreting available multisensory information and presenting content to the human through selected human senses. Sub-classes include augmented vision, hearing, haptic sensation, smell, and taste.

- Augmented action is achieved by sensing human actions and mapping them to actions in local, remote or virtual environments. Sub-classes include motor augmentation, amplified force, and movement, speech input, gaze-based controls, teleoperation, remote presence, and others.

- Augmented cognition (aka enhanced cognition) is achieved by detecting human cognitive state, using analytical tools to make a correct interpretation of it, and adapting computer's response to match the current and predictive needs of the user (e.g., providing stored or recorded information during natural interaction).

Wearable interactive technology is an essential component in enabling human augmentation. It offers a seamless integration with the physical and digital world around us. It can empower the user with non-invasive and easy to use extensions to interact with smart objects and augmented information of the hybrid physical-virtual world of the future. Human augmentation will serve the user by providing essential, timely information for current tasks and filtering out unnecessary information. Augmented humans can have a personal digital butler, but far beyond the visionary Apple Knowledge Navigator video (Apple, 1987). This scenario is related to human-computer integration (Farooq and Grudin, 2016) which is most closely connected to augmented cognition, utilizing computing resources and artificial intelligence to support the human and to work in parallel with the human. Artificial intelligence assistants may act on our behalf, according to our behavioral patterns and preferences, carrying out a range of simple and complex tasks efficiently.

\footnotetext{
${ }^{1}$ https://www.augmented-human.com/

${ }^{2} \mathrm{http}: / /$ human20.com/

${ }^{3}$ https://www.springer.com/engineering/computational+intelligence+and+complexity/journal/41133
} 
Crossmodal interaction allows the characteristics of one sensory modality to be transformed as stimuli for another. This can benefit people with disabilities as well as the elderly with deteriorating sensory abilities. According to Lacey and Sathian (2015), crossmodal interaction can be used to mediate and create cognitive information and to provide access to our spontaneous and socialemotional processes. Crossmodal interaction can be a strong method to build useful and viable elements of human augmentation. In fact, researchers such as Demattè et al. (2006) have already been trying to evaluate how our brain performs crossmodal interaction and how it may be possible to expand the boundaries even further within spontaneous cognitive responses as well as in socialemotional scenarios.

Fig. 2 shows our extension to Milgram's virtuality-reality continuum (Milgram and Kishino, 1994), where the additional $y$-axis is the level of augmentation (number of employed sensors or tools, or the level of augmented cognition). Augmented human uses elements from AR, VR, ubiquitous computing and other user interface paradigms, but merges them in novel ways.

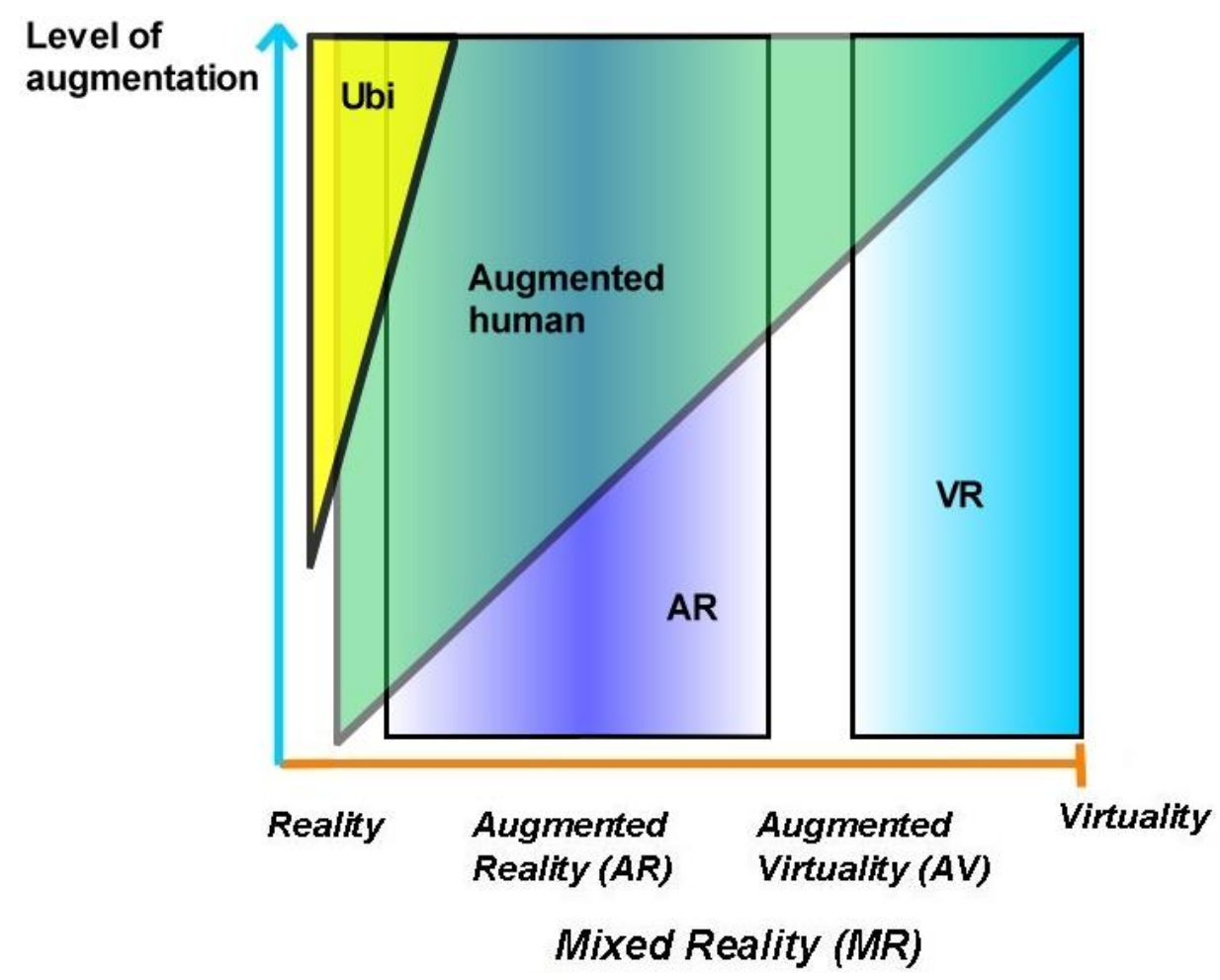

Fig. 2. An extension to Milgram's virtuality-reality continuum (Milgram and Kishino, 1994), where the y-axis is the level of augmentation. Augmented human merges several technologies and UI paradigms to serve humans through more direct and natural interfaces.

Various other concepts and models in computer science, such as ubiquitous computing, perceptual user interfaces, wearable computing, augmented reality, virtual agents, connected devices, robots, and human-computer integration may also provide blueprints for the future in human augmentation. All the concepts and models have a slightly different scope from each other, however, they all focus on different aspects and features of the same augmented-human future.

In the following section, we discuss the state-of-the-art in different areas of human augmentation: augmented senses, augmented action, and augmented cognition. This is followed by our proposed 
model for wearable augmentation, a call for research and potential benefits and applications. And lastly, we take a look at various aspects of ethical and societal issues.

\section{Past and present in human augmentation}

In this Section, we present a summary of existing human-technology interaction research relevant to human augmentation. We have included examples of different approaches in augmented senses, action, and cognition. The aim of the Section is to familiarize the reader with methods, systems, and experiments that show both the extensive potential and the variety of disciplines involved in this field.

\subsection{Augmented senses}

Augmented senses use methods and technologies to either compensate for sensory impairments (mostly visual and auditory) or to exceed the capabilities of existing senses. In the first case, the sensory signals for the impaired senses are amplified significantly or supplemented through other healthy senses. For example, haptic actuators can be used to describe surroundings to a blind person (Maidenbaum et al., 2014; Shull and Damian, 2015) or speech signals to a deaf person (Novich and Eagleman, 2015). In the second case, the human senses are augmented by using additional sensors to observe signals beyond normal human sensory capabilities and transforming them to a suitable format for human use (Evreinov et al., 2017; Farooq, 2017). Many technologies can augment human senses beyond their natural limits. Light sensors or tiny cameras could give "eagle eyes" or night vision to the user, or even go far beyond the human vision wavelengths. A classic example is using " $\mathrm{x}$-ray vision" (Avery et al., 2009) to observe occluded objects.

Visionaries such as Hainich (2009) have been proposing that AR systems can replace much of the current computing hardware and user interfaces. This vision is coming closer to reality step by step in AR systems such as Magic Leap One ${ }^{4}$, Nreal ${ }^{5}$, Focals by North ${ }^{6}$ and Vuzix Blade ${ }^{7}$. Although technological development of the smart glasses is still needed for augmented human applications, studies showing benefits of such systems already exist. For example, we have found that AR interfaces may benefit from auditory and haptic information to augment the human perception of reality (Sand et al., 2015). Other relevant research in this field includes developing calibration-free eye tracking techniques that are used with visual, auditory and haptic feedback (Kangas et al., 2016), and providing haptic guidance for directing one's gaze (Rantala et al., 2017a). Recent work in combining gaze interaction and haptic feedback (Rantala et al., 2017b; Kangas et al., 2017) proves that these two modalities can be used in a seamless manner to support user's main goals in wearable interaction. To push forward the technological development of wearable VR/AR glasses, we have recently invented several extensions for them. Our proof-of-concept prototype (Sand et al., 2015) enables users to touch and feel virtual 3D objects without the need for wearable devices. A superwide field-of-view (FOV) optical design for VR glasses (Rakkolainen et al., 2016; Rakkolainen et al., 2017b) can cover even the full human FOV. Recently we have also experimented with extending the FOV of a VR viewing device (Rakkolainen et al., 2017a) and providing visual feedback for a smart glass user directly to the retina - surpassing the eye and its lens (Koskinen et al., 2017). A combination of pan-tilt-superzoom and 360-degree cameras can provide a zoomable gigapixel experience for a VR viewer (Koskinen et al., 2018).

\footnotetext{
${ }^{4}$ https://www.magicleap.com/magic-leap-one

${ }^{5}$ https://www.nreal.ai/

${ }^{6}$ https://www.bynorth.com/

${ }^{7}$ https://www.vuzix.com/products/blade-smart-glasses
} 
Further examples of exciting augmentation technologies include, for example, "haptic eyes" that let the user feel what the camera sees (Tsetserukou, 2011) or "aided eyes" that enhance the users' cognitive abilities by automatically identifying and matching currently viewed objects with previously saved information (Ishiguro et al., 2010). Spectral extensions enable humans to see beyond visible light spectrum (Richards, 2011) or to hear sub- or supersonic sounds. Such sensors and cameras can be embedded in AR glasses. Near-infrared (IR) and near-ultraviolet (UV) light cameras can expand the range of human senses. In addition, they are very low-cost. Modern thermal (longwave) IR cameras can also be low-cost and extremely small, and they open intriguing possibilities for various applications such as the ability to see in total darkness without any illumination. Security and safety applications inside and outside of vehicles, offices or homes are also potential mainstream applications for these sensors.

Examples of augmented audition are smart headphones, or "hearables", which enhance the hearing experience and natural abilities. These "wearables for the ear" not only mitigate hearing loss and improve hearing in noisy environments but may also catalyze super hearing (McGreal, 2018). They can help to filter out noise, discriminate sounds, or transpose the sound frequency to a level that is easier to perceive (Kirchberger and Russo, 2016). Smart hearing technology can enhance spatial sense or help in focusing on the sound coming from a specific direction (Ricketts, 2001). Furthermore, realworld sounds can be augmented by virtual sound elements, creating a hybrid sound experience and a personalized sound environment (Härmä et al., 2004; Garcia-Espinosa et al., 2015). Due to the closeness of the blood vessels in the ear, the earpiece could incorporate additional sensors to measure physiological signals. This further improves its utility regarding, for example, health and sportsrelated applications (Da He et al., 2015).

Augmented sense of smell can be achieved by measuring or producing scents. State-of-the-art technologies can measure scents, which are undetectable by human olfaction system, thus improving the ability to "smell" hazardous substances (Wilson and Baietto, 2009). Combination of odor measurement technologies and artificial intelligence (AI) algorithms can achieve odor detection accuracy beyond human olfactory capacity (Müller et al., 2019). The human sense of smell can also be augmented by producing artificial odors (Nakamoto, 2016; Yanagida and Tomono, 2013). Odor augmentation can add pleasant experiences for example to VR (Salminen et al., 2018).

Similar approaches have been developed to augment the sense of taste. Sensors that can identify any given taste as sweet, savory, bitter and sour are relatively easy to build (Ranasinghe et al., 2017). However, production of taste sensations has proven to be difficult, as it is closely related to the sense of smell and partly it is also a personal experience. Even though electric actuators to stimulate taste buds in tongue have been proposed (Nakamura and Miyashita, 2011; Ranasinghe and Do, 2017) these have not gained popularity. Mostly, augmented taste sensations concentrate on flavor, meaning that olfactory cues are used to convey an illusion of taste (Narumi et al., 2011).

Augmented senses can also enable sensory substitution or sensory prosthesis, in which information from one sense can be mediated through a different sense (see examples of sensory substitution: Kristjánsson et al., 2016; Wright et al., 2015). This could be done by comparing haptic and audio modalities in order to aid movement and navigation in low-vision environments (Kerdegari et al., 2016). A tactile helmet can be used to mediate information in addition to vision and hearing to improve control (Bertram et al., 2013). More importantly, in extreme environments such as in space, deep in the ocean or buildings that are on fire, the ability of sensors to work in harsh conditions is essential (Alfadhel et al., 2016).

Further techniques for building augmented senses include sensors designed for specific uses such as cameras for very dim light or for non-visible spectrum, auditory or vibration sensors within mobile 
devices or even large-scale sensor arrays, such as networks of remote sensors continuously broadcasting environmental information and global positioning systems for tracking movements of objects and individuals. Integrating these with distributed sensor networks, such as smart traffic systems and location-specific information sources, can increase our awareness of the surrounding world. No matter which type of sensors are being used or what their configuration is, augmented sensing has the potential to increase visual acuity, auditory reception, olfaction threshold, gustatory perception, and haptic sensation beyond the current natural human abilities. Yet with the addition of all these sensors the amount of various sensory information will increase exponentially, therefore, it will be critical how this information is processed and presented to the individual user with reference to its context, task and general need over the course of time.

\subsection{Augmented action}

The earliest examples of augmenting human action were related to motion augmentation. For instance, prosthetic limbs restored some of the capabilities of an amputated limb. Recently, new digital technologies have enabled augmenting action in ways that go beyond natural human motor and sensory limits. For example, exoskeletons enable paralyzed people to walk on robotic feet (Dollar and Herr, 2008; Young and Ferris, 2017). Exoskeletons and dual-arm power amplification solutions (Gopura et al., 2016; Perry et al., 2007) are useful in a range of tasks that are traditionally done by humans but cannot yet be fully automated because they require human intelligence. One potential use case is manual handling of goods where exoskeletons enable humans to lift heavier items and reduce the pressure in the lower back area (see, for example, the Cray X exoskeleton ${ }^{8}$ ). The concept of an exoskeleton can be extended to virtual exoskeletons where a robot placed in a remote location is operated in synchrony with the user's movements (Tachi, 2013). The use of a virtual exoskeleton can be highly immersive if the user wears VR glasses and sees from the robot's perspective. This type of remote presence based on human-robot interaction is especially useful if the operating environment is hazardous and therefore placing a human operator at the site is not safe. Examples of use cases include factories, atomic power plants, assembly operations in space or the sea, and search and rescue operations (Kim et al., 2015; Tachi, 2013).

It is also possible to utilize other input methods such as touch, gestures, gaze and speech to augment human actions in VR or in machinery control. In VR, hand-held controllers, gloves and similar systems are often used to enable virtual limbs that can manipulate objects of any size and weight (e.g., Lee et al., 2017; King et al., 2009; Viau et al., 2004). Gestures can be used to augment action from distance. Controlling machinery over a distance by a mere wave of the hand or other gesture can appear to an observer as use of telekinetic powers (see Agrawal and Gupta, 2016; Bikos et al., 2015; Lee and Lee, 2018 as examples of gesture input). However, gesture-based augmented movement often triggers a phenomenon named as "Midas Touch Problem". This means that a user accidentally makes selections and confirmations. One solution to solve the problem is to use a virtual interface to mediate gestures (Liu et al., 2016). Furthermore, progress in automated speech recognition has enabled more accurate use of voice commands for VR and robotic control (Ferracani et al., 2017; Pleva et al., 2017). In an ideal case, human-computer speech interaction is adaptive, meaning that the machine can correctly interpret the speech despite the user's capabilities or limitations (Loch et al., 2018). It is also possible to control virtual environments by using gaze or head movement (Khamis et al., 2018; Thies et al., 2018; Toyama et al., 2014).

Many of the augmented action examples also require a feedback loop to transmit sensory data to the user. For example, tactile feedback systems can make the use of virtual limbs more accurate (e.g.,

\footnotetext{
${ }^{8} \mathrm{https}: / /$ www.germanbionic.com/en/crayx/
} 
King et al., 2009), force sensors can mediate tactile information measured by a robot to the user (Tsuji et al., 2009), and artificial skin can restore a sense of touch to a prosthetic hand (Antfolk et al., 2014). To best support augmented action, sensory feedback should replicate the real-life functioning of human sensory modalities and emotions (Gavrilovska and Rakovic, 2016; Gavrilovska et al., 2017). In many cases, successful augmentation of action requires synthesizing multisensory information gathered from the environment and utilizing the human sensory system to control action in an adaptive manner (Burdea et al., 1996; Rubio-Tamayo, 2017). Our everyday physical living environment is becoming smarter when more things are connected to each other through Internet of Things. This allows us to sense our environment in new ways and also to interact with it by direct and natural means, such as gestural and spoken interaction. Potential ways to interact with the environment include using gaze control supported with tactile input and feedback (Kangas et al., 2014a; Klamka et al., 2015; Hepperle and Wölfel, 2017) or combining gaze with gestures (Kangas et al., 2014b).

To enable the next step in augmented action, it is necessary to understand the user's cognitive state by measuring, for example, the human brain. This leads us to advanced augmented action technologies such as neuroprosthetics (Leuthardt et al., 2009) that can enable thought control for remote robots (Warwick et al., 2004) and control of prosthetic fingers with a brain-machine interface (Hotson et al., 2016). A possible result of this line of progress is to merge humans and computers with highly-developed implant technologies to create biotechnology-based hybrids (see, for example, Warwick, 2015). Currently, this is still a distant future reminding more of science fiction than stateof-the-art research. However, there are also non-invasive methods for measuring the user's cognitive state as discussed in the next subsection.

\subsection{Augmented cognition}

Augmented cognition is a form of human-technology interaction where a tight coupling between a user and a computer is achieved via physiological and neurophysiological sensing of the user's cognitive state (Stanney et al., 2009a). Augmented cognition integrates information detected from the user to adapt computer input to match the user's situational needs. Therefore, a closed loop between the user and the technological interface is formed (Young et al., 2004; Schmorrow et al., 2006; De Greef et al., 2007). From the beginning, augmented cognition has been a multidisciplinary field of research combining expertise from cognitive psychology, neuroscience, computer science, engineering, and HCI (e.g., Engelbart, 1962; Miller and Dorneich, 2006).

The ultimate goal of the research is to extend user's cognitive abilities and to seamlessly create a functioning augmented cognition that can easily be used to overcome and accommodate bottlenecks, limitations (e.g., decision making or cognitive overload), and biases in human cognition and information processing chain (De Greef et al., 2007; Schmorrow et al., 2005). Schmorrow et al. (2006) argue that augmented cognition can support human information processing related to sensory memory (e.g., enhancing sensory perception), working memory (e.g., supporting simultaneous processing of data from multiple sources), attention (e.g., directing attention), and executive function (e.g., directing recall of previous information so that incoming information can be interpreted optimally). Also, optimizing user's cognitive load while interacting with a computer is commonly seen as a central task for augmented cognition (e.g., De Greef et al., 2007).

Augmented cognitive abilities include extended memory and virtually unlimited knowledge. This can be achieved by using a centralized network to enable extended cognition (see, for instance, Smart, 2017 for a recent review on extended cognition and internet). Augmented cognition has already been used to monitor one's health (Reeder et al., 2017), assist patients suffering from mild brain injuries (Stanney et al., 2009b), and enhancing learning and memory (Palmer and Kobus, 2007; Dingler et 
al., 2016). Tools like life-logging (i.e., storing images and pictures to support memory) can be beneficial for augmented cognition (e.g., Sellen et al., 2007).

However, the seamless integration between existing human perceptual and cognitive abilities and mechanisms to control them is currently missing from the field (Schmidt, 2017). This is required to augment or extend human cognition in real use cases. Most previous studies have concentrated on testing a method to detect cognitive (Steveninck and Laughlin, 1996) or affective state of the user by using one measurement technique. In neuroscience, methods have been developed to monitor, facilitate, and modulate human brain functioning (Eaton and Illes, 2007; Shook and Giordano, 2016; White et al., 2015). For example, electrodes can be implanted into the brain to restore memory functions (Song et al., 2015; Serruya and Kahana, 2008).

Due to invasiveness and ethical concerns of such methods, other solutions are more popular for human-technology interaction. Wearable sensors can measure, for example, electroencephalography, facial muscle activity or sweat gland activity. These measurements can be used to detect one aspect of cognitive state like workload or confusion reliably (Erdogmus et al., 2005; Lecuyer et al., 2013; Abbass et al., 2014; Aricò et al., 2016; Nourbakhsh et al., 2012; Nourbakhsh et al., 2017; Hardy et al., 2013; Durso et al., 2012). At some degree, also human emotions can be tracked down successfully (e.g., Mavridou et al., 2017).

Human cognition can also be detected without any wearable sensors. Infrared, ultrasound, and biofeedback loops have been used to track down brain activity in order to, for example, facilitate learning in VR (Izzetoglu et al., 2004; Argento et al., 2017; Rey et al., 2009). Speech prosody captured by a voice recorder reflects the level of cognitive workload (e.g., Huttunen et al., 2011), and eye movement behavior measured by a gaze tracker or camera can reflect cognitive workload and the emotional state (Ikehara and Crosby, 2005; Marshall, 2007; DeLucia et al., 2014).

But in order to achieve a truly symbiotic relationship between human cognition and computer, unimodal methods described above are not sufficient. Instead, multidimensional measurements are needed (e.g., Skinner et al., 2014; Schwarz and Fuchs, 2017). This means that several technologies are combined to track down different aspects of human cognitive and emotional functioning. For example, by combining measurement of autonomous nervous system activity like cardiac activity and respiration rate with eye tracking, it has already been possible to increase task complexity based on individual learning (Fortin-Côté et al., 2018) and estimate cognitive workload (Nourbakhsh et al., 2013). Skinner et al. (2014) further suggest that in an ideal case the methods used to detect user state should be unobtrusive. They note that current state-of-the-art requires developing multimodal means to detect a human state in such a way that the devices and analyzing tools are optimized to work outside the laboratory (e.g., wearable devices and developing toolkits to interpret the data on the go).

Thus, in real user cases multiple sources of data need to be integrated and interpreted so that the system response works in real time and is context-sensitive (Fuchs and Schwarz, 2017; Fuchs et al., 2007; Patel et al., 2017). To make the loop between the user and the computer seamless, 10iocybernetics adaptation (e.g., Stephens et al., 2018) and similar methods can be considered. This also means that it is necessary to develop mathematical models (Markowsky and Nyquist, 2017) in order to understand augmented cognition (e.g., Young et al., 2004). Artificial intelligence can be used to process vast amounts of sensor data (see, e.g., Blanchard et al., 2009 for using AI to detect user's affective state crucial for learning, or $\mathrm{Li}$ and $\mathrm{Ji}, 2005$, about using Bayesian networks to detect user's affect in real time).

Finally, one long-term goal in human-technology interaction is to use the knowledge of human cognition to build machines that can think like humans. Zheng et al. (2017) and Ren et al. (2017) 
suggest that hybrid-augmented intelligence could take cognition way beyond human abilities. Unlike the current implementation of AI systems, hybrid-augmented intelligence does not require large data sample sizes or extensive data modeling and evolution. Instead, utilizing an intelligent data structuring model combining human cognition with machine learning or by creating software and hardware structures mimicking the working of the human brain itself computer's cognitive capabilities could be improved. Even though this type of computing is still in its infancy, such systems can someday improve the safety, reliability, and predictability of complex dynamic decision-making systems. These systems also have the advantage of replicating human thinking, and, thereby, truly expanding human cognition.

\section{Vision for the future}

In this Section, we first introduce a summarizing model that helps to identify different parts and connections of a wearable augmented human system. Then, we propose a call for research needed to make this vision a reality. To show the potential of the paradigm, we provide examples of how augmented human senses, action and cognition will affect humanity.

\subsection{A model for wearable augmentation}

There is an extensive amount of related research, as introduced in the previous Section. However, human augmentation is missing architectures and models that integrate individual contributions as a holistic approach that could be further used as a basis for practical applications. Next, we present a model for wearable augmentation: augmenting human senses, action and cognition through wearable technology. The starting point is that the technology will enhance human abilities directly, not through an external tool that is manipulated through an interface. Interaction should be as close to actual human action as possible, which leads to a need for tracking human activities used as inputs for the augmentation system.

The proposed enabling technologies for wearable augmentation (see Fig. 3) are as follows:

- Sensing technologies detect the environment, objects, and events. These include pattern recognition and other computer vision methods, auditory sensors, spatial, thermal and movement sensors, multispectral cameras, and touch, olfactory and gustatory sensors.

- Multisensory presentation technologies support attention, memory, and perception; it is achieved through light-weight multimodal mixed reality glasses, crossmodal information presentation, and wearable accessories. It applies different human senses: sight, hearing, touch, olfaction, gustation as channels to mediate augmented sensing and feedback on augmented actions.

- Human activity measurement technologies are based on different wearable sensors. Human activities are recognized as inputs through, for example, speech recognition, motor activity tracking, eye tracking, and force and touch input. Based on this low-level information, human activities are modeled at a higher level.

- Actuation technologies are used to affect the environment as directed by the human. These include different kinds of visual displays, audio equipment, haptic actuators as well as smell and taste generators. In immersive environments, also the sense of balance may be affected through the generation of forces and human pose. 
- Ubiquitous information services and artificial intelligence technologies will provide access to networked information services, internet of things and artificial intelligence support. This will enable to develop personalized AI extensions that can assist and autonomously support a variety of tasks that users are unable or unwilling to perform (Bharucha et al., 2009).

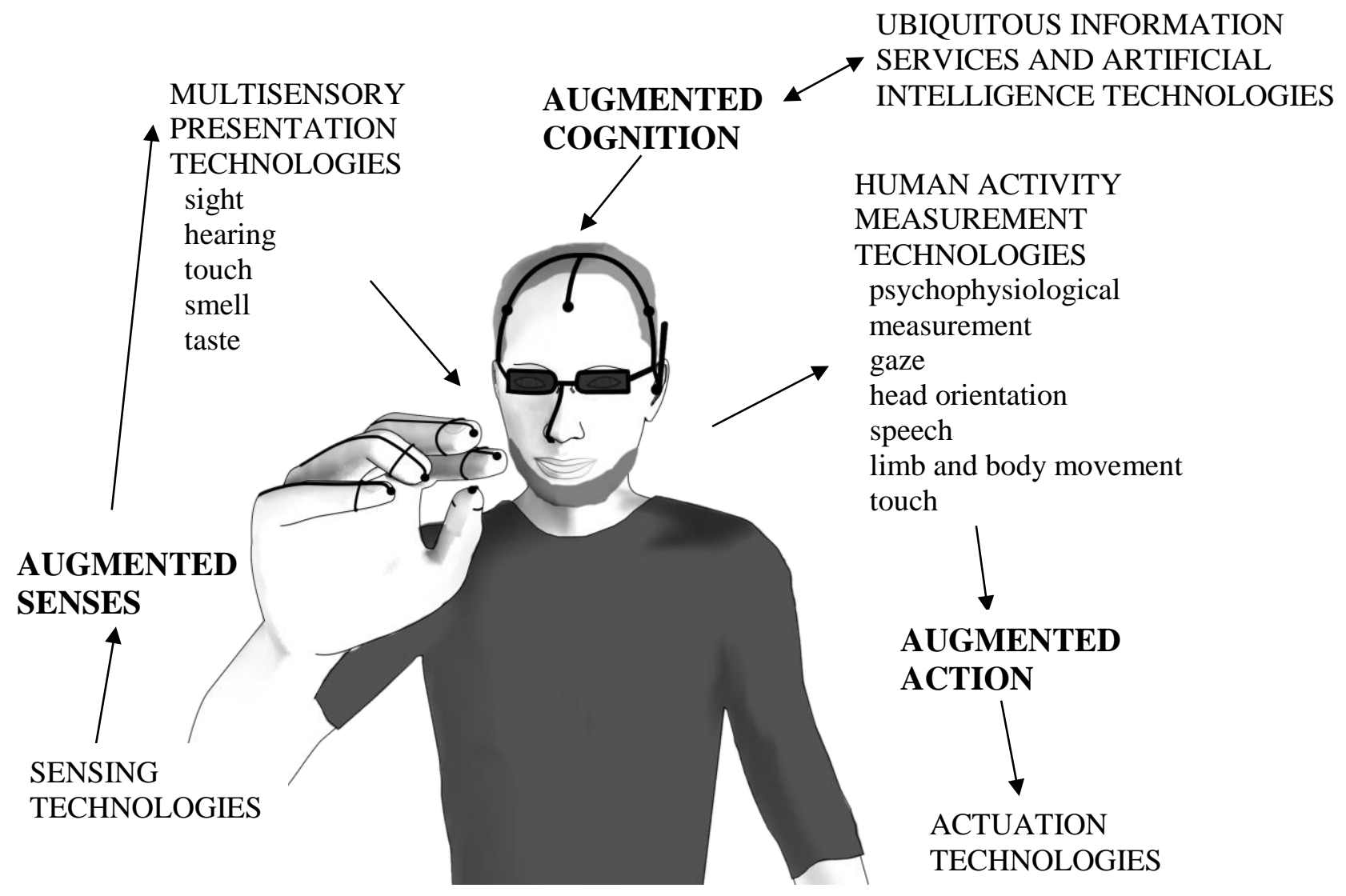

Fig. 3. Information flow and related technologies in wearable augmentation.

Augmented human is a new user interface paradigm, which merges and expands many of the old paradigms (see Fig. 4 e). Our model for wearable augmentation alters the real world beyond augmented interaction (Fig. $4 \mathrm{~d}$ ). Numerous sensors and cloud data provide information, artificial intelligence filters it and it is presented in easy-to-understand ways to support human cognition in a timely manner. Physical tools or robots enable action in and changes to the environment. 




(a) GUI

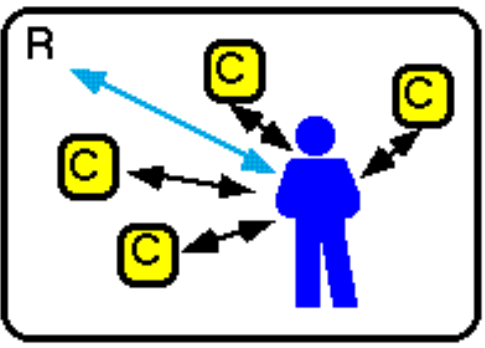

(c) Ubiquitous Computers

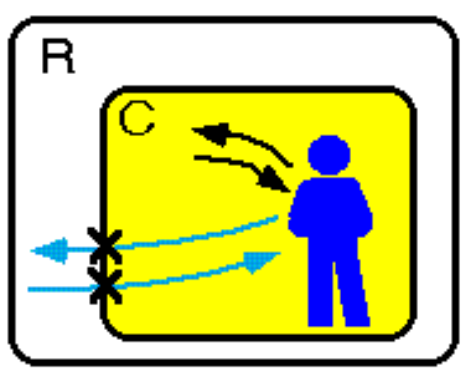

(b) Virtual Reality

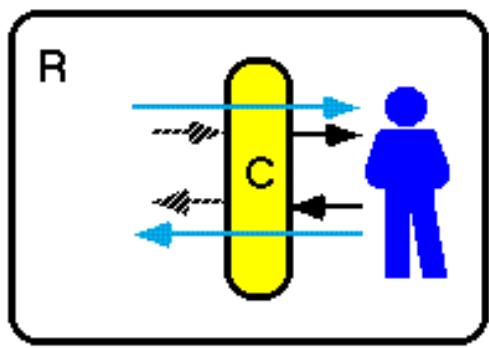

(d) Augmented Interaction

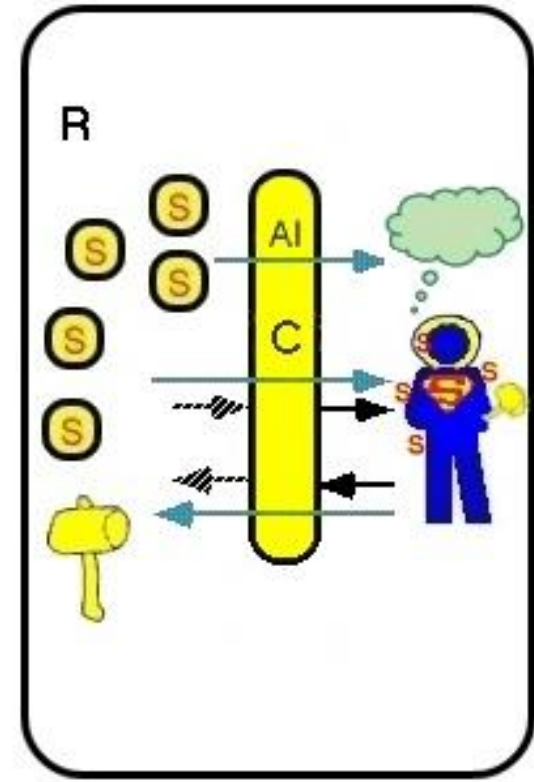

(e) Augmented Human
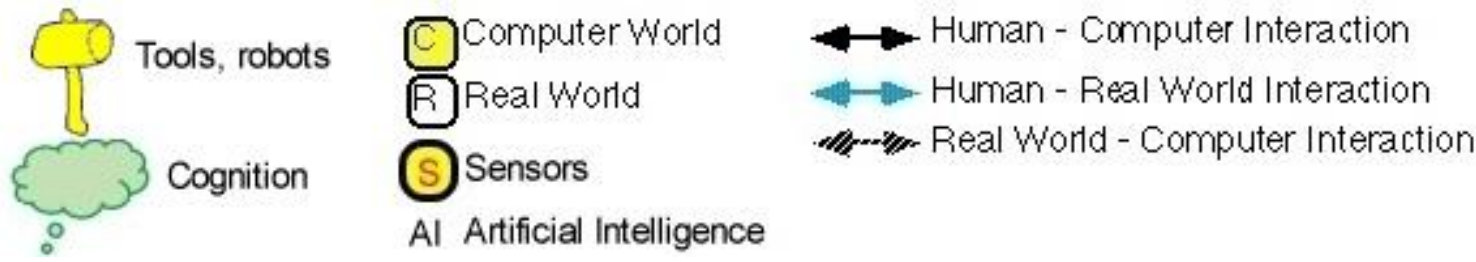

II.-.m Real World - Computer Interaction

Fig. 4. Augmented human is a new UI paradigm, which merges many of the old paradigms. Our model (e) for wearable augmentation expands the real world far beyond augmented interaction (d).

Fig. 4 is an extension to Fig. 1 (Rekimoto and Nagao, 1995).

It should be noted that human augmentation does not mean focusing on individualism. Actually, augmented humans may be better aware of each other and have a close connection approaching to something that feels like a direct brain connection. At its best, other people are brought close to us, independent of where they are physically located. At its worst, privacy and autonomy may be threatened. We discuss the potential benefits in Section 3.3 and ethical and societal concerns in Section 4.

\subsection{Call for research}

Augmented Human is already being realized, step by step. It is becoming better, smaller, and cheaper along the way. Even so, the vision of wearable human augmentation is still largely unrealized, even if many needed pieces of technology already exist. It draws elements from fields such as AR, VR, ubiquitous computing, AI, and sensing technologies, but merges them and takes them much further. In practice, the research being proposed will build on established research into interaction technologies. Realizing the vision will require research at least in the following areas: 
1. Paradigm: define an overall interaction paradigm and metaphors that enable to benefit from augmented senses, action and cognitive abilities. This paradigm shift will require openminded exploratory research in human-technology interaction.

2. Technology: conduct research on sensing and actuation technologies, crossmodal presentation of information, artificial intelligence, context modeling, and integration of multimodal and multisensory information.

3. Experimental research: conduct experimental basic research on how humans can utilize augmented senses, action, and cognitive mechanisms: validating the paradigm, metaphors, interaction techniques, and information presentation methods being used.

4. Applied research: utilize augmented human technologies in everyday systems and applications. Carry out field studies making use of solutions in real life. Collect guidelines to allow wide utilization of the technologies in both science and practice.

5. Theory and models: build a basis for theory on wearable human augmentation based on experimental research. Model different aspects of augmented senses, action and cognition. Model dynamics of applying these technologies in interactive systems.

6. Ethics and societal research: study what it means that humans evolve through augmentation technologies. Includes ethical aspects related to the availability and use of such technologies, such as concerns for equality, misuse, and unfair competitive advantage.

In summary, areas 1-5 are about establishing a technological foundation for wearable human augmentation in a way that utilizes knowledge and views from all stakeholders in the research community. However, technological development and research should not be carried out in isolation without considering the ethical, societal and philosophical aspects of human augmentation. Attitudes towards human augmentation need to be taken into account to build augmentation technology that is accepted both by society and individuals.

\subsection{Future human abilities}

A recent survey (Whitman, 2018) on attitudes towards human enhancement technologies positioned different technologies along a 5-step continuum of use: 1) therapeutic use to restore ability, 2) prevention when there is a known risk or relevant family history, 3) prevention when no known risk or family history is apparent, 4) enhancement beyond the ability one would normally have, and 5) enhancement greatly beyond normal. The results showed that $95 \%$ of respondents supported physical restorative applications. Technological aids for individuals with lower capacities due to age or illness would serve as a critical support mechanism ensuring that the deterioration of senses does not limit the ability to function in the society. The Western, Japanese and Chinese populations are aging fast. As disability rates increase with age, there is an urgent need to find new ways to cope with and fight against age-related disabilities ${ }^{9}$. The proposed human augmentation can potentially push the retirement age further and enable better and longer independent living. It should be noted that technological augmentation does not solve all problems; people still need to take care of their physical and psychological wellbeing by eating well, exercising and resting.

When designing augmentation technology for restoring capabilities, user experience and social acceptability should be considered carefully: they affect people's willingness to utilize the technology. The augmentation should genuinely feel like a part of the user's natural abilities and not like technical tools. It should not require the user to wear technology or perform actions that feel

\footnotetext{
${ }^{9}$ https://www.who.int/news-room/fact-sheets/detail/disability-and-health
} 
uncomfortable or look weird to bystanders (Akkil et al., 2016). Even if highly beneficial, high-tech aids are often rejected by the elderly who do not want to highlight their disability (Yusif et al., 2016). The stigma of assistive aids should be kept in mind when designing discreet augmentation technology. Recent advances in sensing technologies make it possible to embed sensors in clothes (McCann and Bryson, 2009), regular eyeglass frames (Amft et al., 2015) or jewelry (Lappalainen et al., 2016) so that they do not draw unwanted attention.

There are also psychological factors that may hinder the adoption or adherence to technological aids. For example, the confidence of operating the technology yields higher motivation to continued use, highlighting the importance of learnability, ease-of-use, and sense of being in control (Tuazon et al., 2018). When successful, even traditional assistive aids such as the wheelchair can feel "part of me" (Barker et al., 2004). Obviously, the technology does not come without cost. The benefits need to exceed the costs - not only the financial costs but also the extra effort that comes with learning, using and maintaining the technology. Even if people are eager to try out new technology, it does not guarantee long-term adoption (Clawson et al., 2015).

As we move forward in the 5-step continuum of enhancement technologies (Whitman, 2018), the technology is used for enabling abilities one would not normally have. For example, in the case of hearing loss - be it due to a medical condition or to temporarily noisy environment - visual or haptic feedback can be used to represent the information (Hoggan et al., 2009; Nanayakkara et al., 2013). Similarly, vision loss can be compensated by auditory or haptic feedback (Pietrzak et al., 2007; Csapó et al., 2015), making it possible to enjoy activities such as skiing (Aggravi et al., 2016). Gaze-based interaction makes it possible to communicate simply by moving the eyes (Majaranta et al., 2011), augmenting the action capabilities of people who cannot move or speak. Utilizing the same technology, anybody can browse a public screen - remotely, simply by looking at it (Vidal et al., 2013). Exoskeletons can compensate for a disability or support workers for example by controlling their posture, or give super strength for industrial workers (Luo and Yu, 2013; Chu et al., 2014).

Sensation augmentation can compensate for the missing sensation of numbness and help in preventing pressure sores (Rush, 2009), or it may enhance experiences with extraordinary feelings (Neidlinger et al., 2017). Augmented senses may also amplify empathy by replicating other people's experiences (Werfel et al., 2016). Cognitive augmentation with lifelogging provides the much-needed memory support for people with dementia (Tokunaga et al., 2016), but can also be useful for any busy citizen who appreciates the ability to recall events and activities in their personal life (Gurrin, 2014). Also the environment and surrounding objects can act as interactive mediators for the augmented senses and action. A walking cane could "see" the environment and may thus assist to navigate a person with deteriorating vision (Ju et al., 2009). Sensors in a car may act like an external skin that augments the driver's sense of the environment (Ochiai and Toyoshima, 2011), and augment the driving, for example, by haptic feedback (Nukarinen et al., 2015).

As we move to the far end of Whitman's 5-step continuum (2018), people perceive enhancement technology more and more negatively. Less than 35\% of the respondents supported boosting of performance with interventions intended purely for upgrading a physical or cognitive ability. The main reason was that such technology introduces several ethical and societal problems. For example, as Bavelier et al. (2019) point out, augmented vision or greater cognitive capabilities could be useful for a warfighter in the future. But does this mean that anyone who wishes to join the army should undergo human enhancement? What happens when the fighters leave the army and the enhancement technology is no longer needed? Furthermore, enhanced memory could be beneficial for a student preparing for an exam, yet detrimental to the community. 


\section{Ethical and societal discussion}

Human enhancement or augmentation can be understood as an individual choice creating value for the user (Menuz et al., 2013). This does not exclude raised concerns related to the effects of human augmentation to individuals and society in general (e.g., Bavelier et al., 2019; Heimo et al., 2014). Already now when human augmentation is taking its first steps, users have valid practical concerns related to the new human augmentation technologies that can weigh more than personal experiences and benefits. Overall, human augmentation is a leap to the unknown, and neglecting potential negative effects of such technologies to daily life and society can create undesirable scenarios for the future. There will surely be many unintended consequences. In the following section, we investigate practical concerns related to individual rights and concerns as well as scenarios related to potential threats to society. Finally, some solutions are offered to solve these complex problems.

\subsection{Problems related to individual users}

\subsubsection{Privacy}

The novel human augmentation technologies are often being developed by large organizations. This means that collecting enormous amounts of data from the users, advertising, promoting interest of the organization, and getting profit from them has effects on the ethics in this field. As the interaction technologies become more and more pervasive and at some point even invasive, the ownership of the collected data, access by third parties to the data, and regulation of the content creation becomes a significant issue. For example, augmented cognition enables the collection of information from the brain which violates privacy in unimaginable way compared to the current technologies (Wahlstrom et al., 2011). Further, memory assistance such as life-logs can create a situation in which information is never forgotten (Dodge and Kitchin, 2007). It is easy to envision how systems that log and analyze events, people, and places using text, audio and visual material create a situation in which access to such sensitive data and controlling it can be harmful to individuals. This is especially true if there is no possibility to erase the logged data. As large amounts of very personal and detailed data are collected by different sensors and data sources, data handling procedures and privacy are important (e.g., Glenn and Monteith, 2014).

\subsubsection{Social manipulation}

As augmented technologies are by nature very pervasive, it can be extremely difficult to distinguish between real and unreal events, and thus subtle manipulation can be impossible to detect and suppress. The augmented sensing technologies may easily be programmed to contain erroneous information. Even more invasive brain-computer interfaces and other neurotechnology applications can overcome sensory stimulation and thus create a potential for manipulation. Already the contemporary artificial intelligence techniques can be used to create fabricated visual and auditory information (Maras and Alexandrou, 2018), which endangers information credibility. Since augmented sensory experiences can be created, for example, by a large company, the creator of the technology has the power to control what the user sees or hears (e.g., Brinkman, 2014). Even though this may seem like an irrelevant concern, it offers the potential for manipulating the user through life-like augmented and pervasive sensory experiences.

\subsubsection{Autonomy and side effects}

In respect to autonomy, a common threat is a situation related to sensory overload, in which information is no longer efficiently processed (Kristjánsson et al., 2016). There are also concerns related to patient autonomy and responsibility in case of an accident when technologies are utilized, for instance, by patients suffering from neurodegenerative diseases (Clausen, 2011). Wolf et al. 
(2016) note that the ability to share a sensory experience like one's visual field is a valid threat to autonomy. The most complex ethical concerns arise from augmented cognition. Especially neurotechnological implants and chemical stimulants can be extremely harmful to the user through side effects, or to the society in terms of creating a potential for terrorism (e.g., Cakic, 2009; Kotchetkov et al., 2010; Tennison and Moreno, 2012; Forlini et al., 2013).

\subsubsection{Accessibility}

Universal access is a serious problem when technologies capable of exceeding the natural abilities of humans are being developed. Most often, the reason behind the inclusion of the novel technologies is simply the cost. However, technologies can be inaccessible for special user groups like hearing impaired or elderly (Obrenovic et al., 2007). Augmented senses, in general, can be seen mostly as creating positive impacts for the people in need of sensory assistance. However, the group benefitting the most from the augmented senses is very diverse. While in the other end of the continuum are young millennials who can suffer from, for example, hearing problems but use technological devices and assistance seamlessly, other groups like hearing impaired elderly can suffer from problems even while using simple smartphone applications. For the elderly, the potential of novel technologies easily creates a conflict between an actual need and the combination of independence, dignity and privacy (Fugger et al., 2007). Augmented action can bring out somewhat similar concerns as augmented senses. Again, the diversity of people benefitting the most from the technologies can create unbearable challenges for the designers. Universal access is the most studied societal issue in the field of augmented technologies. For example, using enhancement technologies to increase one's abilities while excluding some groups outside similar benefits can threaten equality in society (Bostrom and Roach, 2008; Eaton and Illes, 2007).

\subsection{Societal concerns}

\subsubsection{Safety and balance}

As with any other technology, human augmentation can also be used against certain sections of society. Although technology can be used to combat segregation, inequality and oppression of minorities, human history is also filled with examples of the opposite. Already mechanical data processing with punch cards enabled to conduct a genocide very efficiently (Black, 2001). With current supercomputers, sensors, connected devices at home and offices, big data, artificial intelligence and augmentation technologies, only sky is the limit. Surveillance systems with face recognition and other technologies can extend the control of citizens to unprecedented levels and the dictators of rogue states are using them to secure their power. Orwell's novel "1984" is becoming frighteningly true. An augmented human with its many personal and intimate sensors may enable to go even beyond that.

As already mentioned, augmented technologies can be used for social manipulation. It is clear that such usage of the novel technologies can have significant negative effects on the society which go far beyond the current social manipulation of advertising and social media. As Rosling et al. (2018) have noted, the information and the worldview that the mainstream media feeds to us is often very outdated and simply wrong in many essential aspects of the state of the world. Also, social media is feeding us with filtered news and information which are suitable for our own specific bubbles. We expect the same to happen in various ways with augmented information.

The new technologies used for social control are not a big problem under benevolent government, as they are also beneficial (to root out terrorism, to immediately call an ambulance when needed, etc.), but they may become a Pandora's box. Perhaps also the good societies will degenerate to right-wing, left-wing or green fascism after the next major recession or war. It is not necessarily only the 
governments which try to control their subservient. A similarly grim vision would be that social media and ICT giants could try to influence elections, laws, policies, buying habits or worldviews, or by grabbing selected fields of power from governments. However, the big tech companies and governments are not competitors but rather collaborators, because they have many vested interests.

\subsubsection{Unpredictable future}

Some of the effects of novel technologies are related to economics (Hughes, 2014; Nica, 2016). Augmented action, sensing and artificial intelligence are known to be able to reduce the need for human labor force meaning that a large amount of population could face unemployment. The effect will be the largest with people working with routine tasks (Peng et al., 2018), and not so surprisingly, uneducated workers are already worried about their future (McClure, 2018). Overall, it seems that technology can increase the disparity in working life (e.g., Nica, 2016). On the other hand, mankind has gone through quite many disruptive technologies such as steam engines, electricity, industrialization, tractors, cars, atomic power and automation, and as a result, we are now better off than ever (Rosling et al. 2018). The digital divide in population and other related issues are rather complex (e.g., Van Dijk and Hacker, 2003). The potential effects are quite serious issues and should not be overlooked when adapting novel technologies in workplaces or in our personal lives.

In augmented action, ethical concerns are closely related to interaction design (Verbeek, 2006). The rules how to act in shared, virtual, or augmented realities by using augmented motoric movement and action are in the hotspot of successful ethical implementation of this field of research. What can the users, avatars and robots do? How can they manipulate their surroundings? Are they capable, for example, to violence?

Augmented cognition is creating a situation in which mankind is taking a giant leap forward (Saniotis et al., 2014). In the scope of this article, it needs to be understood that human cognition, as well as brain functions or artificial neural networks mimicking and helping cognition, are not fully understood. The following example can be used to illustrate the point. EEG measures brain activity and an AI algorithm analyses the data to make interpretations of the user's state. However, EEG activity can be a result of various cognitive processes. In addition, AI methods have their limitations, and when large amounts of data are being processed, it can be impossible to understand why the AI method makes a particular prediction. Without taking these restrictions seriously, we lose the ability to plan the potential effects augmented cognition can have on individuals and society. Overall, it seems that in this field, public policies and regulation will be needed (see, for example, Bostrom and Sandberg, 2009, for suggestions).

Finally, in the field of bioenhancement and genetic manipulation the effects of human augmentation to the future generations are unknown (Giubilini and Sanyal, 2015). Firmino and Duarte (2010) further note, that urban life as such will be revolutionized by digitalization as control of space and movement are fundamentally changed.

\subsection{Solutions to mitigate ethical problems}

All the ethical issues raised in the field of human-technology interaction can mostly be overcome by creating international guidelines, standards and laws for ensuring privacy, safety, equality and better design for user interfaces. Inclusive HCI design approach can also offer some solutions to the problem (Abascal and Azevedo, 2007). For example, the need to control personal data privacy is already acknowledged in the European Union's General Data Protection Regulation (GDPR). Similarly, it can be noted that social inequality issues were a concern when smartphones were introduced, but nowadays also the poor use them and benefit from the technology. 
By stretching human abilities beyond their natural limits, it is possible to fundamentally change society for better or worse. History shows that any technology can and will be used for both good and bad. By considering ethical questions before implementing new technical solutions to augment humans, one can envision how to use them to create a better and more equal future for us all.

\section{Conclusions}

Human beings have always been striving to improve their natural abilities. This need to evolve has shaped human development and what it means to be human. However, gradual natural evolution may soon take a backseat as human beings take control of their own future. We as a species are now more capable of altering and enhancing ourselves than ever before. The need to be stronger, faster, and smarter has contributed to a vast number of scientific developments. A large number of technologies from gene therapy to exoskeleton attachments and from brain-computer interfaces to having the entire global repository of information at one's fingertips can soon enhance and alter our abilities. Some of these technologies are still in their infancy and need to mature over time. However, many technologies can already be integrated to augment core human abilities.

At the moment, most of these technologies are used independently with little to no fusion. As demonstrated in this paper, creating an integrated, intelligent wearable system is the next essential step in the progression of augmenting human abilities. The once diversified technologies with variable use cases are now coalescing into a robust framework that lays the foundation for the Augmented Human of the future. This advancement will revolutionize the meaning of being human. However, due to ethical issues related to such augmentation, regulation as well as international standards and guidelines are essential for ensuring privacy, universal access, etc. to such technologies. Augmentation technology should not only enhance the well-being and quality of life of an individual but also have positive effects on the community and society.

Sir Arthur C. Clarke, a science fiction author and futurist once stated: "any sufficiently advanced technology is indistinguishable from magic ${ }^{10}$ ". Human augmentation is one of the fields where recent advancements have a clear potential for making this a reality. Wearable augmentation technologies and related interaction methods provide an excellent opportunity to realize the possibilities enabled by modern science and technology, benefiting humanity in unprecedented ways.

\section{Acknowledgments}

This research was supported by the following institutions: Tampere University, Strategic Research Development Programme in Human-Technology Interaction; The Finnish Funding Agency for Innovation (Tekes), project Virtual and Augmented Reality Content Production and Use (decision \#1444/31/2016); and the Academy of Finland, project Augmented Eating Experiences (decision \#316804/2018).

\footnotetext{
${ }^{10}$ Clarke's Third Law in Profiles of the Future (revised edition, 1973) by Arthur C. Clarke
} 


\section{References}

Abascal J., Azevedo L., 2007. Fundamentals of Inclusive HCI Design. In: Stephanidis C. (eds) Universal Access in Human-Computer Interaction. Coping with Diversity. UAHCI 2007. Lecture Notes in Computer Science, vol 4554. Springer, Berlin, Heidelberg

Abbass, H.A., Tang, J., Amin, R., Ellejmi, M., Kirby, S., 2014. Augmented cognition using realtime EEG-based adaptive strategies for air traffic control. In: Proceedings of the human factors and ergonomics society annual meeting $(58,1)$. SAGE Publications, pp. 230-234.

Aggravi, M., Salvietti, G., Prattichizzo, D., 2016. Haptic assistive bracelets for blind skier guidance. In: ACM Int. Conf. on Augmented Human (AH'16). ACM, Article 25.

Agrawal, R., Gupta, N., 2016. Real time hand gesture recognition for human computer interaction. In: IEEE 6th International Conference on Advanced Computing (IACC), pp. 470-475.

Akkil, D., Lucero, A., Kangas, J., Jokela, T., Salmimaa, M., Raisamo, R., 2016. User Expectations of Everyday Gaze Interaction on Smartglasses. In: Proceedings of the 9th Nordic Conference on Human-Computer Interaction (NordiCHI '16). ACM. Article 24.

Alfadhel, A., Khan, M.A., Cardoso, S., Leitao, D., Kosel, J., 2016. A magnetoresistive tactile sensor for harsh environment applications. Sensors, 16 (5), 650.

Alicea, B., 2018. An Integrative Introduction to Human Augmentation Science. arXiv, 1804.10521.

Amft, O., Wahl, F., Ishimaru, S., Kunze, K., 2015. Making regular eyeglasses smart. IEEE Pervas. Comput. 14 (3), 32-43.

Antfolk, C., Kopta, V., Farserotu, J., Decotignie, J.D., Enz, C., 2014. The WiseSkin artificial skin for tactile prosthetics: A power budget investigation. In: 8th International Symposium on Medical Information and Communication Technology (ISMICT). IEEE, pp. 1-4.

Apple, 1987. Knowledge Navigator video, https://www.youtube.com/watch?v=JIE8xk6R11w.

Argento, E., Papagiannakis, G., Baka, E., Maniadakis, M., Trahanias, P., Sfakianakis, M., Nestoros, I., 2017. Augmented Cognition via Brainwave Entrainment in Virtual Reality: An Open, Integrated Brain Augmentation in a Neuroscience System Approach. Augment. Hum. Res. 2 (1), 3.

Aricò, P., Borghini, G., Di Flumeri, G., Colosimo, A., Pozzi, S., Babiloni, F., 2016. A passive brain-computer interface application for the mental workload assessment on professional air traffic controllers during realistic air traffic control tasks. Prog. Brain Res. 228, 295-328.

Avery, B., Sandor, C., Thomas, B.H., 2009. Improving spatial perception for augmented reality xray vision. In: 2009 IEEE Virtual Reality Conference. IEEE, pp. 79-82. http://doi.org/10.1109/VR.2009.4811002

Bertram, C., Evans, M.H., Javaid, M., Stafford, T., Prescott, T., 2013. Sensory augmentation with distal touch: the tactile helmet project. In: Conference on Biomimetic and Biohybrid Systems. Springer, Berlin, Heidelberg, pp. 24-35.

Barker, D. J., Reid, D., Cott, C. 2004. Acceptance and meanings of wheelchair use in senior stroke survivors. Am. J Occup. Ther. 58 (2), 221-230.

Bavelier, D., Savulescu, J., Fried, L., Friedmann, T., Lathan, C., Schürle, S., Beard, J., 2019. Rethinking human enhancement as collective welfarism. Nature 3 (3), 204-206.

Bharucha, A., Anand, V., Forlizzi, J., Amanda M., Reynolds, C., Stevens, S., Wactlar H., 2009. Intelligent Assistive Technology Applications to Dementia Care: Current Capabilities, Limitations, and Future Challenges. Am. J. Geriat. Psychiat. 17 (2), 88-104

Bikos, M., Itoh, Y., Klinker, G., Moustakas, K., 2015. An interactive augmented reality chess game using bare-hand pinch gestures. In: International Conference on Cyberworlds (CW). IEEE, pp. 355-358. 
Black, E., 2001. IBM and the Holocaust: The Strategic Alliance Between Nazi Germany and America's Most Powerful Corporation. Crown.

Blanchard, E.G., Volfson, B., Hong, Y.J., Lajoie, S.P., 2009. Affective artificial intelligence in education: From detection to adaptation. In: AIED 2009, pp. 81-88.

Bostrom, N., Roache, R., 2008. Ethical issues in human enhancement. New waves in applied ethics, 120-152.

Bostrom, N., Sandberg, A., 2009. Cognitive enhancement: methods, ethics, regulatory challenges. Sci. Eng. Ethics 15 (3), 311-341.

Brinkman, B., 2014. Ethics and pervasive augmented reality: Some challenges and approaches. In: Emerging Pervasive Information and Communication Technologies (PICT). Springer, Dordrecht, pp. 149-175.

Burdea, G., Richard, P., Coiffet, P., 1996. Multimodal virtual reality: Input-output devices, system integration, and human factors. Int. J. Hum.-Comput. Int. 8 (1), 5-24.

Cakic, V., 2009. Smart drugs for cognitive enhancement: ethical and pragmatic considerations in the era of cosmetic neurology. J. Med. Ethics 35 (10), 611-615.

Chu, G., Hong, J., Jeong, D. H., Kim, D., Kim, S., Jeong, S., Choo, J. 2014. The experiments of wearable robot for carrying heavy-weight objects of shipbuilding works. In: 2014 IEEE International Conference on Automation Science and Engineering (CASE). IEEE, pp. 978-983.

Clausen, J., 2011. Conceptual and ethical issues with brain-hardware interfaces. Curr. Opin. Psychiatr. 24 (6), 495-501.

Clawson, J., Pater, J., Miller, A., Mynatt, E., Mamykina, L., 2015. No longer wearing: investigating the abandonment of personal health-tracking technologies on craigslist. In: Proceedings of the 2015 ACM International Joint Conference on Pervasive and Ubiquitous Computing, 647-658.

Csapó, Á., Wersényi, G., Nagy, H., Stockman, T., 2015. A survey of assistive technologies and applications for blind users on mobile platforms: a review and foundation for research. $J$. Multimodal User In. 9 (4), 275-286.

Da He, D., Winokur, E., Sodini, C., 2015. An Ear-Worn Vital Signs Monitor. IEEE T. Biomed. Eng. 62 (11), 2547-255T. 2.

De Greef, T., van Dongen, K., Grootjen, M., Lindenberg, J., 2007. Augmenting cognition: reviewing the symbiotic relation between man and machine. In: International Conference on Foundations of Augmented Cognition. Springer, Berlin, Heidelberg, pp. 439-448.

DeLucia, P.R., Preddy, D., Derby, P., Tharanathan, A., Putrevu, S., 2014. Eye movement behavior during confusion toward a method. In: Proceedings of the Human Factors and Ergonomics Society 58th Annual Meeting, 58 (1), pp. 1300-1304. doi:10.1177/1541931214581271.

Demattè, M., Sanabria, D., Sugarman R., Spence C., 2006. Cross-modal interactions between olfaction and touch. Chem. Senses, 31 (4), 291-300.

Dingler, T., El Agroudy, P., Le, H., Schmidt, A., Niforatos, E., Bexheti, A., Langheinrich, M., 2016. Multimedia memory cues for augmenting human memory. IEEE MultiMedia 23 (2), 4-11.

Dodge, M., Kitchin, R., 2007. 'Outlines of a world coming into existence': pervasive computing and the ethics of forgetting. Environ. Plann. B: planning and design 34 (3), 431-445.

Dollar, A.M., Herr, H., 2008. Lower Extremity Exoskeletons and Active Orthoses: Challenges and State-of-the-Art. IEEE T. Robotics, 24 (1), 144-158.

Durso, F., Geldbach, K., Corballis, P., 2012. Detecting confusion using facial electromyography. Human factors, 54 (1), 60-69.

Eaton, M.L., Illes, J., 2007. Commercializing cognitive neurotechnology - the ethical terrain. Nat. biotechnol. 25 (4), 393.

Engelbart, D., 1962. Augmenting human intellect: a conceptual framework. SRI Summary Report AFOSR-3223. 
Engelbart, D., 1968. A demonstration at AFIPS Fall Joint Computer Conference 1968.

Erdogmus, D., Adami, A., Pavel, M., Lan, T., Mathan, S., Whitlow, S., Dorneich, M., 2005. Cognitive state estimation based on EEG for augmented cognition. In: 2nd International IEEE EMBS Conference on Neural Engineering. IEEE, pp. 566-569.

Evreinov, G., Farooq, A., Raisamo, R., Hippula, A., Takahata, D., 2017. Tactile imaging system, United States Patent 9672701 B2.

Farooq, U., Grudin, J., 2016. Human-computer integration. Interactions 23, 6, 26-32.

Farooq, A., 2017. Developing techniques to provide haptic feedback for surface based interaction in mobile devices. Dissertations in Interactive Technology, nr. 26, University of Tampere, Finland. Available at: http://tampub.uta.fi/bitstream/handle/10024/102318/978-952-03-0590-1.pdf

Ferracani, A., Faustino, M., Giannini, G.X., Landucci, L., Del Bimbo, A., 2017. Natural Experiences in Museums through Virtual Reality and Voice Commands. In: Proceedings of the 2017 ACM on Multimedia Conference. ACM, pp. 1233-1234.

Firmino, R., Duarte, F., 2010. Manifestations and implications of an augmented urban life. International Review of Information Ethics 12 (03), 28-35.

Fishkin, K., Moran, T., Harrison, B., 1998. Embodied User Interfaces: Towards Invisible User Interfaces. In: Proceedings of the IFIP TC2/TC13 WG2.7/WG13.4 Seventh Working Conference on Engineering for Human-Computer Interaction. Kluwer, pp. 1-18.

Forlini, C., Hall, W., Maxwell, B., Outram, S., Reiner, P., Repantis, D., Racine, E., 2013. Navigating the enhancement landscape: Ethical issues in research on cognitive enhancers for healthy individuals. EMBO reports, 14 (2), 123-128.

Fortin-Côté, A., Lafond, D., Kopf, M., Gagnon, J.F., Tremblay, S., 2018. Toward Adaptive Training Based on Bio-behavioral Monitoring. In: International Conference on Augmented Cognition. Springer, Cham, pp. 34-45.

Fugger, E., Prazak, B., Hanke, S., Wassertheurer, S., 2007. Requirements and ethical issues for sensor-augmented environments in elderly care. In: Int. Conf. on Universal Access in HumanComputer Interaction. Springer, Berlin, Heidelberg, pp. 887-893.

Fuchs, S., Hale, K.S., Stanney, K.M., Juhnke, J., Schmorrow, D.D., 2007. Enhancing mitigation in augmented cognition. J. Cognitive Engineering and Decision Making, 1 (3), 309-326.

Fuchs, S., Schwarz, J., 2017. Towards a dynamic selection and configuration of adaptation strategies in Augmented Cognition. In: International Conference on Augmented Cognition. Springer, Cham, pp. 101-115.

Garcia-Espinosa, E., Longoria-Gandara, O., Veloz-Guerrero, A., Riva, G., 2015. Hearing aid devices for smart cities: A survey. In: IEEE First Int. Smart Cities Conference (ISC2), pp. 1-5.

Gavrilovska, L., Rakovic, V., 2016. Human Bond Communications: Generic Classification and Technology Enablers. Wireless Pers. Commun. 88: 5. https://doi.org/10.1007/s11277-016-32464

Gavrilovska, L., Rakovic, V., Dixit, S., 2017. General Concepts Behind Human Bond Communications. Human Bond Communication: The Holy Grail of Holistic Communication and Immersive Experience, 11-39.

Giubilini, A., Sanyal, S., 2015. The ethics of human enhancement. Philosophy Compass, 10 (4), 233-243.

Glenn, T., Monteith, S., 2014. Privacy in the digital world: medical and health data outside of HIPAA protections. Curr. Psychiat. Rep. 16 (11), 494.

Gopura, R.A.R.C., Bandara, D.S.V., Kiguchi, K., Mann, G.K.I., 2016. Developments in hardware systems of active upper-limb exoskeleton robots: A review. Robot. Auton. Syst. 75, 203-220.

Gurrin, C., Smeaton, A., Doherty, A., 2014. Lifelogging: Personal big data. Found. Trends Inf. Ret. $8(1), 1-125$. 
Hainich, R., 2009. The End of Hardware, 3rd Edition: Augmented Reality and Beyond. BookSurge Publishing.

Hansen, L., Dalsgaard, P., 2015. Note to self: stop calling interfaces "natural". In: Proceedings of the Fifth Decennial Aarhus Conference on Critical Alternatives. Aarhus University Press, 2015, 65-68.

Hardy, M., Wiebe, E., Grafsgaard, J., Boyer, K., Lester, J., 2013. Physiological responses to events during training: Use of skin conductance to inform future adaptive learning systems. In:

Proceedings of the Human Factors and Ergonomics Society Annual Meeting (57, 1). SAGE Publications, pp. 2101-2105.

Heimo, O., Kimppa, K., Helle, S., Korkalainen, T., Lehtonen, T., 2014. Augmented reality Towards an ethical fantasy?. In: 2014 IEEE Int. Symposium on Ethics in Science, Technology and Engineering, pp. 1-7. IEEE.

Hepperle, D., Wölfel, M., 2017. Do you feel what you see?: multimodal perception in virtual reality. In: Proc. of the 23rd ACM Symp. on Virtual Reality Software and Technology, p. 56.

Hoggan, E., Crossan, A., Brewster, S., Kaaresoja, T., 2009. Audio or tactile feedback: which modality when? In: SIGCHI Conference on Human Factors in Computing Systems. doi:10.1145/1518701.1519045

Hotson, G., McMullen, D., Fifer, M., Johannes, M., Katyal, K., Para, M., Armiger, R., Anderson, W., Thakor, N., Wester, B., Crone, N., 2016. Individual finger control of a modular prosthetic limb using high-density electrocorticography in a human subject. J. Neural Eng. 13 (2), 26017. http://doi.org/10.1088/1741-2560/13/2/026017

Hughes, J., 2014. Are Technological Unemployment and a Basic Income Guarantee Inevitable or Desirable?. Journal of Evolution and Technology, 24 (1), 1-4.

Huttunen, K., Keränen, H., Väyrynen, E., Pääkkönen, R., Leino, T., 2011. Effect of cognitive load on speech prosody in aviation: Evidence from military simulator flights. Applied ergonomics, 42 (2), 348-357.

Härmä, A., Jakka, J., Tikander, M., Karjalainen, M., Lokki, T., Hiipakka, J. Lorho, G., 2004. Augmented reality audio for mobile and wearable appliances. J. Audio Eng. Soc. 52 (6), 618639.

Ikehara, C.S., Crosby, M.E., 2005. Assessing cognitive load with physiological sensors. In: the 38th Annual Hawaii Int. Conf. on System Sciences 2005. IEEE, p. 295a.

Ishiguro, Y., Mujibiya, A., Miyaki, T., Rekimoto, J., 2010. Aided eyes: eye activity sensing for daily life. In: ACM Int. Conf. on Augmented Human (AH'10). ACM, Article 25.

Izzetoglu, K., Bunce, S., Onaral, B., Pourrezaei, K., Chance, B., 2004. Functional optical brain imaging using near-infrared during cognitive tasks. Int. J. Hum.-Comput. Int. 17 (2), 211-227.

Jerald, J., 2015. The VR Book: Human-Centered Design for Virtual Reality. Morgan \& Claypool Publishers.

Ju, J.S. Ko, E., Kim, E.Y. 2009. EYECane: navigating with camera embedded white cane for visually impaired person. In: Proceedings of the 11th international ACM SIGACCESS conference on Computers and accessibility (ASSETS'09). ACM, pp. 237-238.

Kangas, J., Akkil, D., Rantala, J., Isokoski, P., Majaranta, P., Raisamo, R., 2014b. Gaze gestures and haptic feedback in mobile devices. In: the 2014 annual conference on Human factors in computing systems (CHI'14). ACM, pp. 435-438.

Kangas, J., Rantala, J., Akkil, D., Isokoski, P., Majaranta, P., Raisamo, R., 2017. Vibrotactile Stimulation of the Head Enables Faster Gaze Gestures. Int. J. Human-Comput. Studies, 98, 6271. 
Kangas, J., Rantala, J., Majaranta, P., Isokoski, P., Raisamo, R., 2014a. Haptic Feedback to Gaze Events. In: the Symposium on Eye Tracking Research and Applications (ETRA'14). ACM, pp. 11-18.

Kangas, J., Špakov, O., Isokoski, P., Akkil, D., Rantala, J., Raisamo, R., 2016. Feedback for Smooth Pursuit Gaze Tracking Based Control. In: ACM Int. Conf. on Augmented Human (AH'16). ACM, Article 6.

Kerdegari, H., Kim, Y., Prescott, T.J., 2016. Head-mounted sensory augmentation device: comparing haptic and audio modality. In: Conference on Biomimetic and Biohybrid Systems. Springer, Cham, pp. 107-118.

Khamis, M., Oechsner, C., Alt, F., Bulling, A., 2018. VRpursuits: interaction in virtual reality using smooth pursuit eye movements. In: 2018 International Conference on Advanced Visual Interfaces (AVI'18). ACM.

Kim, J.H., Starr, J.W. Lattimer, B.Y., 2015. Firefighting Robot Stereo Infrared Vision and Radar Sensor Fusion for Imaging through Smoke. Fire Technology 51: 823. https://doi.org/10.1007/s10694-014-0413-6

King, C.H., Culjat, M.O., Franco, M.L., Lewis, C.E., Dutson, E.P., Grundfest, W.S., Bisley, J.W., 2009. Tactile feedback induces reduced grasping force in robot-assisted surgery. IEEE T. haptics, 2 (2), 103-110.

Kirchberger, M., Russo, F.A. 2016. Harmonic Frequency Lowering: Effects on the Perception of Music Detail and Sound Quality. Trends Hear, 20: 1-12.

Klamka, K., Siegel, A., Vogt, S., Göbel, F., Stellmach, S., Dachselt, R., 2015. Look \& pedal: Hands-free navigation in zoomable information spaces through gaze-supported foot input. In: 2015 ACM International Conference on Multimodal Interaction. ACM, pp. 123-130.

Koskinen, E., Rakkolainen, I., Raisamo, R., 2017. Direct Retinal Signals for Virtual Environments. In: 2017 ACM Symposium on Virtual Reality Software and Technology (VRST 2017). ACM, Article 55.

Koskinen, O., Rakkolainen, I., Raisamo, R., 2018. Gigapixel Virtual Reality Employing Live Superzoom Cameras. The 24th ACM Symp. on Virtual Reality Software and Technology (VRST 2018). ACM, Article 92.

Kotchetkov, I., Hwang, B., Appelboom, G., Kellner, C., Connolly, E., 2010. Brain-computer interfaces: military, neurosurgical, and ethical perspective. Neurosurg. Focus 28 (5), E25.

Kristjánsson, Á., Moldoveanu, A., Jóhannesson, Ó.I., Balan, O., Spagnol, S., Valgeirsdóttir, V., Unnthorsson, R., 2016. Designing sensory-substitution devices: Principles, pitfalls and potential 1. Restor. Neurol. Neuros. 34 (5), 769-787.

Lacey, S., Sathian, K., 2015. Crossmodal and multisensory interactions between vision and touch. Scholarpedia journal, 10 (3), 7957.

Lappalainen, T., Virtanen, L., Häkkilä, J., 2016. Experiences with wellness ring and bracelet form factor. In: Proceedings of the 15th International Conference on Mobile and Ubiquitous Multimedia. ACM, pp. 351-35.

Lecuyer, A., George, L., Marchal, M., 2013. Toward adaptive VR simulators combining visual, haptic, and brain-computer interfaces. IEEE Comput. Graph. 33 (5), 18-23.

Lee, T., Lee, H., 2018. A New Virtual Keyboard with Finger Gesture Recognition for AR/VR Devices. In: Kurosu M. (ed) Human-Computer Interaction. Interaction Technologies. HCI 2018. Lecture Notes in Computer Science, vol 10903. Springer, Cham.

Lee, S., Park, K., Lee, J., Kim, K., 2017. User study of VR basic controller and data glove as hand gesture inputs in VR games. In: 2017 International Symposium on Ubiquitous Virtual Reality (ISUVR). IEEE, pp. 1-3. 
Leuthardt, E.C., Schalk, G., Roland, J., Rouse, A., Moran, D.W., 2009. Evolution of brain-computer interfaces: going beyond classic motor physiology. Neurosurgical focus, 27 (1), E4.

Li, X., Ji, Q., 2005. Active affective state detection and user assistance with dynamic Bayesian networks. IEEE T Syst. Man Cyb. 35 (1), 93-105.

Lipkie, D.E., Evans, S.R., Newlin, J.K., Weissman, R.L., 1982. Star graphics: an object-oriented implementation. In: Proceedings of ACM SIGGRAPH '82, Comp. Graph. 16 (3), 115-124.

Liu, H., Feng, Z., Liang, L., Xu, Z., 2016. Virtual Interface and Its Application in Natural Interaction. In: Pan, Z., Cheok, A., Müller, W., Zhang M. (eds) Transactions on Edutainment XII. Lecture Notes in Computer Science, vol 9292. Springer, Berlin, Heidelberg.

Loch, F., Czerniak, J., Villani, V., Sabattini, L., Fantuzzi, C., Mertens, A., Vogel-Heuser, B., 2018. An Adaptive Speech Interface for Assistance in Maintenance and Changeover Procedures. In: International Conference on Human-Computer Interaction. Springer, Cham, pp. 152-163.

Luo, Z., Yu, Y., 2013. Wearable stooping-assist device in reducing risk of low back disorders during stooped work. In: 2013 IEEE International Conference on Mechatronics and Automation. IEEE, pp. 230-236.

Maidenbaum, S., Hanassy, S., Abboud, S., Buchs, G., Chebat, D., Levy-Tzedek, S., Amedi, A., 2014. The "EyeCane", a new electronic travel aid for the blind: Technology, behavior \& swift learning. Restor. Neurol. Neuros. 32 (6), 813-824. http://doi.org/10.3233/RNN-130351

Majaranta, P., Aoki, H., Donegan, M., Hansen, D.W., Hansen, J.P., Hyrskykari, A., Räihä, K.-J., (Eds.) 2011. Gaze Interaction and Applications of Eye Tracking: Advances in Assistive Technologies. IGI Global.

Maras, M. H., Alexandrou, A. 2018. Determining authenticity of video evidence in the age of artificial intelligence and in the wake of Deepfake videos. The International Journal of Evidence \& Proof: 1365712718807226.

Markowsky, G., Nyquist, H., 2017. Information Theory (Mathematics). Online Britannica Article, Encyclopaedia Britannica, inc. (Accessed May 2, 2019).

https://www.britannica.com/science/information-theory/Physiology

Marshall, S., 2007. Identifying cognitive state from eye metrics. Aviat. Space Envir. MD. 78 (5), B165-B175.

Mavridou, I., McGhee, J., Hamedi, M., Fatoorechi, M., Cleal, A., Balaguer-Ballester, E., ... Nduka, C., 2017. FACETEQ: A novel platform for measuring emotion in VR. In: Proceedings of the Virtual Reality International Conference-Laval Virtual 2017. ACM, p. 9.

Maybury, M.T., Wahlster, W. 1998. Readings in intelligent user interfaces. Morgan Kaufmann Publishers, San Francisco.

McCann, J., Bryson, D. (Eds.), 2009. Smart clothes and wearable technology. Elsevier.

McClure, P., 2018. "You're Fired," Says the Robot: The Rise of Automation in the Workplace, Technophobes, and Fears of Unemployment. Soc. Sci. Comput. Rev. 36 (2), 139-156.

McGreal, R., 2018. Hearables for Online Learning. Int. Rev. Res. Open Dis. 19 (4).

Menuz, V., Hurlimann, T., Godard, B., 2013. Is human enhancement also a personal matter?. Sci. Eng. Ethics 19 (1), 161-177.

Milgram, P., Kishino, F., 1994. A taxonomy of mixed reality visual displays. IEICE T. Informat. Sys., 77 (12), 1321-1329.

Miller, C.A., Dorneich, M.C., 2006. From associate systems to augmented cognition: 25 years of user adaptation in high criticality systems. In: The Augmented Cognition conference. Poster.

Moore, P., 2008. Enhancing me: the hope and the hype of human enhancement. Wiley / Dana Centre. 
Müller, P., Salminen, K., Nieminen, V., Kontunen, A., Karjalainen, M., Isokoski, P., ... Lekkala, J., 2019. Scent classification by $\mathrm{K}$ nearest neighbors using ion-mobility spectrometry measurements. Expert Syst. Appl. 115, 593-606.

Nakamoto (Ed). 2016. Essentials of machine olfaction and taste. John Wiley \& Sons.

Nakamura, H., Miyashita, H., 2011. Augmented gustation using electricity. In: ACM Int. Conf. on Augmented Human (AH'11). ACM, Article 34.

Nanayakkara, S., Wyse, L., Ong, S., Taylor, E., 2013. Enhancing musical experience for the hearing-impaired using visual and haptic displays. Human-Comput. Interact. 28 (2), 115-160.

Narumi, T., Nishizaka, S., Kajinami, T., Tanikawa, T., Hirose, M., 2011. Augmented reality flavors: gustatory display based on edible marker and cross-modal interaction. In: Proceedings of the SIGCHI conference on human factors in computing systems. ACM, pp. 93-102.

Neidlinger, K., Truong, K. P., Telfair, C., Feijs, L., Dertien, E., Evers, V., 2017. AWElectric: that gave me goosebumps, did you feel it too?. In: Proceedings of the Eleventh International Conference on Tangible, Embedded, and Embodied Interaction. ACM, pp. 315-324.

Nica, E., 2016. Will technological unemployment and workplace automation generate greater capital-labor income imbalances?. Economics, Management, and Financial Markets, 11 (4), 6874.

Nourbakhsh, N., Wang, Y., Chen, F., Calvo, R.A., 2012. Using galvanic skin response for cognitive load measurement in arithmetic and reading tasks. In: Proceedings of the 24th Australian Computer-Human Interaction Conference. ACM, pp. 420-423.

Nourbakhsh, N., Wang, Y., Chen, F., 2013. GSR and blink features for cognitive load classification. In: IFIP Conference on Human-Computer Interaction. Springer, Berlin, Heidelberg, pp. 159-166.

Nourbakhsh, N., Chen, F., Wang, Y., Calvo, R.A., 2017. Detecting users' cognitive load by galvanic skin response with affective interference. ACM T. Interact. Intelligent Sys., 7 (3), 12.

Novich, S.D., Eagleman, D.M., 2015. Using space and time to encode vibrotactile information: toward an estimate of the skin's achievable throughput. Exp. Brain Res. 233 (10), 2777-2788. http://doi.org/10.1007/s00221-015-4346-1

Nukarinen, T., Rantala, J., Farooq, A., Raisamo, R. 2015. Delivering directional haptic cues through eyeglasses and a seat. In: 2015 IEEE World Haptics Conference (WHC 2015). IEEE, pp. 345350.

Obrenovic, Z., Abascal, J., Starcevic, D. 2007. Universal accessibility as a multimodal design issue. Commun. ACM, 50(5), 83-88.

Ochiai, Y. Toyoshima, K. 2011. Homunculus: the vehicle as augmented clothes. In: ACM Int. Conf. on Augmented Human (AH '11). ACM, Article 3.

O'Hara, K., Harper, R., Mentis, H., Sellen, A., Taylor, A., 2013. On the naturalness of touchless: Putting the "interaction" back into NUI. ACM T. Comput-Hum. Int. 20 (1), article 5.

Palmer, E., Kobus, D., 2007. The future of augmented cognition systems in education and training. In: International Conference on Foundations of Augmented Cognition. Springer, Berlin, Heidelberg, pp. 373-379.

Papagiannis, H., 2017. Augmented Human: How technology is shaping the new reality. O'Reilly Media.

Patel, A., Jung, T.P., Sejnowski, T.J., 2017. An Affordable Bio-Sensing and Activity Tagging Platform for HCI Research. In: International Conference on Augmented Cognition. Springer, Cham, pp. 399-409.

Peng, G., Wang, Y., Han, G., 2018. Information technology and employment: The impact of job tasks and worker skills. J. Ind. Rel. 60 (2), 201-223.

Perry, J., Rosen, J., Burns, S., 2007. Upper-Limb Powered Exoskeleton Design. IEEE/ASME T. Mech. 12 (4), 408-417. 
Pietrzak, T., Martin, B., Pecci, I., Saarinen, R., Raisamo, R., Järvi, J., 2007. The MICOLE architecture: multimodal support for inclusion of visually impaired children. In: Proceedings of the 9th international conference on Multimodal interfaces. ACM, pp. 193-200.

Pleva, M., Juhar, J., Cizmar, A., Hudson, C., Carruth, D., Bethel, C, 2017. Implementing English speech interface to Jaguar robot for SWAT training. In: 2017 IEEE 15th Int. Symp. on Applied Machine Intelligence and Informatics (SAMI), pp. 000105-000110.

Rakkolainen, I., Raisamo, R., Turk, M., Höllerer, T., Palovuori, K., 2017b. Extreme Field-of-View for Head-Mounted Displays. In: 11th 3DTV Conference 2017. IEEE, Article 102.

Rakkolainen, I., Raisamo, R., Turk, M., Höllerer, T., 2017a. Field-of-View Extension for VR Viewers. In: 20th International Academic Mindtrek Conference 2017, ACM Press.

Rakkolainen, I., Turk, M., Höllerer, T., 2016. A Compact, Wide-FOV Optical Design for HeadMounted Displays. In: 2016 ACM Symposium on Virtual Reality Software and Technology (VRST 2016), ACM Press, pp. 293-294.

Ranasinghe, N., Do, E.Y L., 2017. Digital lollipop: Studying electrical stimulation on the human tongue to simulate taste sensations. ACM T. Multim. Comput., 13 (1), 5.

Ranasinghe, N., Jain, P., Karwita, S., Yi-Luen Do, E., 2017. Virtual Lemonade: Let's Teleport Your Lemonade! In: Proc. 11th International Conference on Tangible, Embedded, and Embodied Interaction (TEI'17). ACM, pp. 183-190. DOI: 10.1145/3024969.3024977

Rantala, J., Kangas, J., Raisamo, R., 2017a. Directional Cueing of Gaze with a Vibrotactile Headband. In: ACM Int. Conf. on Augmented Human (AH'17). ACM, Article 7.

Rantala, J., Majaranta, P., Kangas, J., Isokoski, P., Akkil, D., Špakov, O., Raisamo, R., 2017b. Gaze Interaction with Vibrotactile Feedback: Review and Design Guidelines. Hum.-Comput. Interact., pp. 1-39. http://dx.doi.org/10.1080/07370024.2017.1306444

Reeder, B., Cook, P. F., Meek, P. M., Ozkaynak, M., 2017. Smart watch potential to support augmented cognition for health-related decision making. In: International Conference on Augmented Cognition. Springer, Cham, pp. 372-382.

Rekimoto J., Nagao, K., 1995. The World through the Computer: Computer Augmented Interaction with Real World Environments. In: Proceedings of UIST'95 Conference. ACM, pp. 29-36.

Ren, P., Ma, Y., Chen, S., Yu, S., ... Wang, F., 2017. Hybrid-augmented intelligence: collaboration and cognition. Front. Inform. Tech. El., 18 (2), 153-179.

Rey, B., Alcañiz, M., Naranjo, V., Tembl, J., Parkhutik, V., 2009. Transcranial Doppler: A Tool for Augmented Cognition in Virtual Environments. In: International Conference on Foundations of Augmented Cognition. Springer, Berlin, Heidelberg, pp. 427-436.

Richards, A., 2011. Alien Vision: Exploring the Electromagnetic Spectrum with Imaging Technology. SPIE Press, Bellingham, WA, USA.

Ricketts, T. A., 2001. Directional Hearing Aids. Westminster Publications.

Robbins, T., 2005. Chemistry of the mind: neurochemical modulation of prefrontal cortical function. J. Comp. Neurol., 493 (1), 140-146.

Rosling H., Rosling Rönnlund A., Rosling O., 2018. Factfulness: Ten Reasons We're Wrong About the World - and Why Things Are Better Than You Think. Flatiron Books.

Rubio-Tamayo, J., Gertrudix Barrio, M., García García, F., 2017. Immersive environments and virtual reality: Systematic review and advances in communication, interaction and simulation. Multimodal Technologies Interact., 1 (4), 21.

Rush, R.P. 2009. Sensation augmentation to relieve pressure sore formation in wheelchair users. In: Proceedings of the 11th international ACM SIGACCESS conference on Computers and accessibility (ASSETS'09). ACM, pp. 275-276.

Saniotis, A., Henneberg, M., Kumaratilake, J., Grantham, J., 2014. "Messing with the mind": evolutionary challenges to human brain augmentation. Front. Syst. Neurosci. 8, 152. 
Salminen, K., Rantala, J., Isokoski, P., Lehtonen, M., Müller, P., Karjalainen, M., Väliaho, J., Kontunen, A., Nieminen, V., Leivo, J., Telembeci, A., 2018. Olfactory Display Prototype for Presenting and Sensing Authentic and Synthetic Odors. In: Proc. International Conference on Multimodal Interaction 2018. ACM, pp. 73-77.

Sand, A., Rakkolainen, I., Palovuori, K., Isokoski, P., Kangas, J., Raisamo, R., 2015. HeadMounted Display with Mid-Air Tactile Feedback. In: ACM Symposium on Virtual Reality Software and Technology (VRST 2015). ACM, pp. 51-58.

Schmalstieg, D., Höllerer, T., 2016. Augmented Reality: Principles and Practice. Addison-Wesley Professional.

Schmidt, A., 2017. Augmenting Human Intellect and Amplifying Perception and Cognition. IEEE Pervas. Comput. (1), 6-10.

Schmorrow, D., Stanney, K. M., Wilson, G., Young, P., 2005. Augmented cognition in humansystem interaction. Handbook of human factors and ergonomics, 3.

Schmorrow, D.D., Stanney, K.M., Reeves, L.M., 2006. Foundations of Augmented Cognition, 2nd ed. Arlington Virginia: Strategic Analysis.

Schwarz, J., Fuchs, S., 2017. Multidimensional real-time assessment of user state and performance to trigger dynamic system adaptation. In: International Conference on Augmented Cognition. Springer, Cham, pp. 383-398.

Sellen, A.J., Fogg, A., Aitken, M., Hodges, S., Rother, C., Wood, K., 2007. Do life-logging technologies support memory for the past?: an experimental study using sensecam. In: Proc. SIGCHI conference on Human factors in computing systems. ACM, pp. 81-90.

Serruya, M.D., Kahana, M.J., 2008. Techniques and devices to restore cognition. Behav. brain res., $192(2), 149-165$.

Shneiderman, B., 1982. The future of interactive systems and the emergence of direct manipulation. Behav. Inform. Technol. 1 (3), 237-256.

Shook, J.R., Giordano, J., 2016. Neuroethics beyond normal: Performance enablement and selftransformative technologies. Camb. Q. Healthc. Ethic., 25 (1), 121-140.

Shull, P.B., Damian, D.D., 2015. Haptic wearables as sensory replacement, sensory augmentation and trainer - a review. J. Neuroeng. Rehabil., 12 (1), 59. http://doi.org/10.1186/s12984-0150055-Z

Skinner, A., Russo, C., Baraniecki, L., Maloof, M., 2014. Ubiquitous augmented cognition. In: International Conference on Augmented Cognition. Springer, Cham, pp. 67-77.

Smart, P., 2017. Extended Cognition and the Internet. Philos. Tech., 30 (3), 357-390.

Song, D., Robinson, B.S., Hampson, R.E., Marmarelis, V.Z., Deadwyler, S.A., Berger, T.W., 2015. Sparse generalized volterra model of human hippocampal spike train transformation for memory prostheses. In: 2015 Int. Conf. of the IEEE Engineering in Medicine and Biology Society (EMBC). IEEE, pp. 3961-3964. http://doi.org/10.1109/EMBC.2015.7319261

Stanney, K.M., Schmorrow, D.D., Johnston, M., Fuchs, S., Jones, D., Hale, K.S. Ahmad, A., 2009a. Augmented Cognition: An Overview. Reviews on Hum. Factors and Ergon. 5 (1), 195-224.

Stanney, K., Hale, K., Jones, D., 2009b. Augmented Cognition Design Approaches for Treating Mild Traumatic Brain Injuries. In: International Conference on Foundations of Augmented Cognition. Springer, Berlin, Heidelberg, pp. 800-809.

Stephens, C., Dehais, F., Roy, R.N., Harrivel, A., Last, M.C., Kennedy, K., Pope, A., 2018. Biocybernetic Adaptation Strategies: Machine Awareness of Human Engagement for Improved Operational Performance. In: International Conference on Augmented Cognition. Springer, Cham, pp. 89-98.

Steveninck R., Laughlin S., 1996. The rate of information transfer at graded-potential synapses NEC research institute. Nature 379, pp. 642-645 
Suthana, N., Haneef, Z., Stern, J., Mukamel, R., Behnke, E., Knowlton, B., Fried, I., 2012. Memory enhancement and deep-brain stimulation of the entorhinal area. New Engl. J. Med. 366 (6), 502510.

Sutherland, I., 1963. Sketchpad, a Man-Machine Graphical Communication System. In: Int. Workshop on Managing Requirements Knowledge (AFIPS), Detroit, 1899, pp. 329.

Tachi, S., 2013. From 3D to VR and further to telexistence. In: 23rd International Conference on Artificial Reality and Telexistence (ICAT 2013). IEEE, pp. 1-10.

Tennison, M., Moreno, J., 2012. Neuroscience, ethics, and national security: the state of the art. PLoS biology, 10 (3), e1001289.

Thies, J., Zollhöfer, M., Stamminger, M., Theobalt, C., Nießner, M., 2018. FaceVR: Real-Time Gaze-Aware Facial Reenactment in Virtual Reality. ACM T. Graphic., 37 (2), 25.

Toyama, T., Sonntag, D., Dengel, A., Matsuda, T., Iwamura, M., Kise, K., 2014. A mixed reality head-mounted text translation system using eye gaze input. In: Proceedings of the 19th international conference on Intelligent User Interfaces. ACM, pp. 329-334.

Tokunaga, S., Horiuchi, H., Takatsuka, H., Saiki, S., Matsumoto, S., Nakamura, M., Yasuda, K. 2016. Towards personalized and context-aware reminder service for people with dementia. In: International Joint Conference on Neural Networks (IJCNN). IEEE, pp. 2946-2953.

Tsetserukou, D., 2011. FlexTorque, FlexTensor, and HapticEye: exoskeleton haptic interfaces for augmented interaction. In: ACM Int. Conf. on Augmented Human (AH'11). ACM, Article 33.

Tsuji, T., Kaneko, Y., Abe, S., 2009. Whole-body force sensation by force sensor with shell-shaped end-effector. IEEE T. Ind. Electron. 56 (5), 1375-1382.

Tuazon, J., Jahan, A., Jutai, J., 2018. Understanding adherence to assistive devices among older adults: a conceptual review. Disability and Rehabilitation: Assistive Technology, 1-10.

Turk, M., 2014. Multimodal interaction: A review. Pattern Recogn. Lett. 36 (15), 189-195.

Van Dijk, J., Hacker, K., 2003. The digital divide as a complex and dynamic phenomenon. Inform. Soc. 19 (4), 315-326.

van Krevelen, D., Poelman, R., 2010. A survey of augmented reality: technologies, applications and limitations. Int. J. Virtual Reality 9 (2):1-20.

Verbeek, P., 2006. Materializing morality: Design ethics and technological mediation. Sci. Technol. Hum. Val. 31 (3), 361-380.

Vidal, M., Bulling, B., Gellersen, H., 2013. Pursuits: spontaneous interaction with displays based on smooth pursuit eye movement and moving targets. In: Proceedings of the 2013 ACM international joint conference on Pervasive and ubiquitous computing (UbiComp'13). ACM, pp. 439-448.

Viau, A., Feldman, A., McFadyen, B., Levin, M., 2004. Reaching in reality and virtual reality: a comparison of movement kinematics in healthy subjects and in adults with hemiparesis. $J$. Neuroeng. Rehabil. 1 (1), 11.

Wahlstrom, K., Fairweather, N., Ashman, H., 2011. Brain-computer interfaces: A technical approach to supporting privacy. Doctoral dissertation, Sheffield Hallam University.

Warwick, K., Gasson, M., Hutt, B., Goodhew, I., Kyberd, P., Schulzrinne, H., Wu, X., 2004. Thought communication and control: a first step using radiotelegraphy. IEE P-Commun. 151 (3), 185.

Warwick, K., 2015. The merging of humans and machines. In Neurotechnology, Electronics, and Informatics. Springer, Cham, pp. 79-89.

Weiser, M., 1993. Some computer science issues in ubiquitous computing. Comm. ACM 36 (7), 75 84. 
Werfel, F., Wiche, R., Feitsch, J., Geiger, C. 2016. Empathizing audiovisual sense impairments: Interactive real-time illustration of diminished sense perception. In: ACM Int. Conf. on Augmented Human (AH'16). ACM, article 15.

White, S., Richey, J., Gracanin, D., Bell, M., LaConte, S., Coffman, M., ... Kim, I., 2015. The promise of neurotechnology in clinical translational science. Clinical Psychological Science, 3 (5), 797-815.

Whitman, D., 2018. U.S. Public Opinion and Interest on Human Enhancements Technology. Washington, DC. https://doi.org/10.26419/res.00192.001

Wilson, A., Baietto, M., 2009. Applications and advances in electronic nose technologies. Sensors, 9 (7), 5099-5148.

Wolf, M., Grodzinsky, F., Miller, K., 2016. There's something in your eye: Ethical implications of augmented visual field devices. J. Inf. Commun. Ethics Soc., 14 (3), 214-230.

Wright, T. D., Margolis, A., \& Ward, J., 2015. Using an auditory sensory substitution device to augment vision: evidence from eye movements. Experimental brain research, 233(3), 851-860.

Yanagida, Y., Tomono, A., 2013. Basics for olfactory display. In: Nakamoto T (Ed). Human Olfactory Displays and Interfaces: Odor Sensing and Presentation. IGI Global, pp. 60-85.

Young, A., Ferris, D., 2017. State of the Art and Future Directions for Lower Limb Robotic Exoskeletons. IEEE T. Neur. Sys. Reh. 25 (2), 171-182.

Young, P., Clegg, B., Smith, C., 2004. Dynamic models of augmented cognition. Int. J. Hum.Comput. Int. 17 (2), 259-273.

Yusif, S., Soar, J., Hafeez-Baig, A. 2016. Older people, assistive technologies, and the barriers to adoption: A systematic review. Int. J. Med. Inform., 94, 112-116.

Zheng, N., Liu, Z., Ren, P., Ma, Y., Chen, S., Yu, S., ... Wang, F., 2017. Hybrid-augmented intelligence: collaboration and cognition. Front. Inform. Tech. El., 18 (2), 153-179. 


\section{Author biographies}

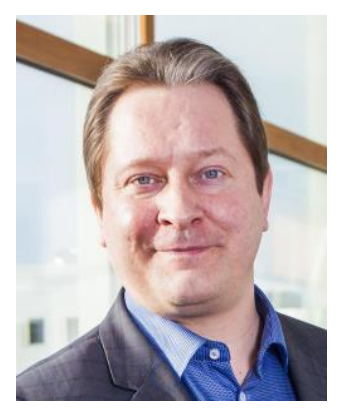

Roope Raisamo is a professor of computer science in Tampere University, Faculty of Information Technology and Communication Sciences. He received his PhD degree in computer science from the University of Tampere in 1999. He is the head of TAUCHI Research Center (Tampere Unit for Computer-Human Interaction), leading Multimodal Interaction Research Group. His 25-year research experience in the field of human-technology interaction is focused on multimodal interaction, XR, haptics, gaze, gestures, interaction techniques, and software architectures.

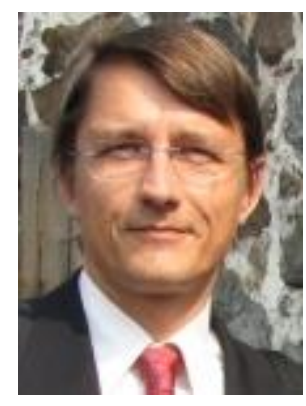

Ismo Rakkolainen received his D.Tech. from the Tampere University of Technology, Tampere, Finland, in 2002. He is a University Research Fellow at the Tampere University, Finland. He has also been the CTO of FogScreen Inc. and a visiting researcher at the Univ. of California. He has published 70 journal and conference papers, 4 book chapters, and has 4 patents. His research interests include interaction techniques, novel user interfaces, displays, and mixed reality.



Päivi Majaranta received her PhD in Interactive Technology (2009) from the University of Tampere, Finland. Her research focuses on human-technology interaction, with special interest on gaze-based interfaces. She also teaches courses on human-centered design and usability evaluation methods at the Tampere University. 


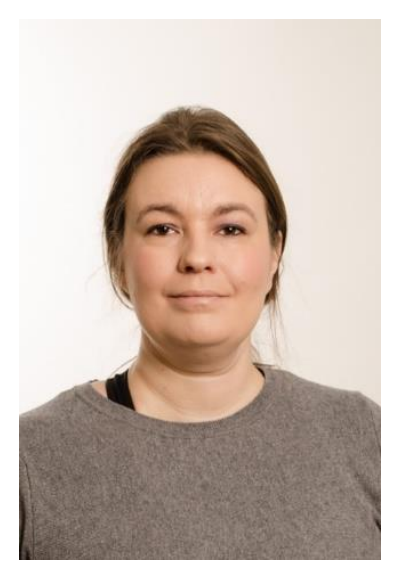

Katri Salminen received the MA degree in psychology (2006) and $\mathrm{PhD}$ in Interactive Technology (2015) from the University of Tampere. She currently works as a postdoctoral researcher at the Tampere Unit of Computer-Human Interaction (TAUCHI) in the Research Group for Emotions, Sociality, and Computing. Her research concentrates on human sense of touch and olfaction.

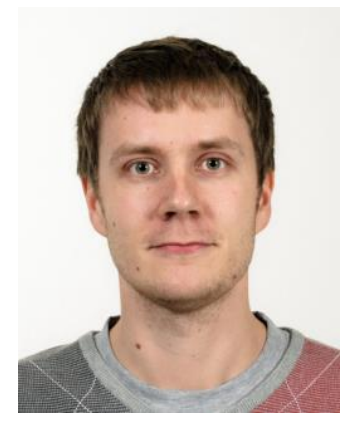

Jussi Rantala received his MSc in Computer Science (2007) and PhD in Interactive Technology (2014) from the University of Tampere. He has worked as a researcher (2006-2014) and postdoctoral researcher (2015-) at the Tampere Unit of Computer-Human Interaction (TAUCHI) at the Tampere University. His research focuses on the use of touch, smell, and gaze in interacting with computers.

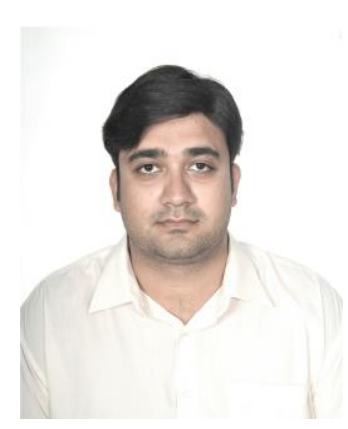

Ahmed Farooq has over 17 years of experience in multimodal interaction technologies and system engineering and has been working at Tampere Unit of Computer-Human Interaction (TAUCHI) Research Center at Tampere University, since 2011. He has a PhD in Interactive Technologies a Masters and Bachelors in Computer Science. For the last few years he has been developing novel interaction techniques for multimodal user interfaces expanding on the concept of Haptic Mediation. In 2019 he is working as a visiting Postdoc Researcher at Purdue University, Indiana, USA. 